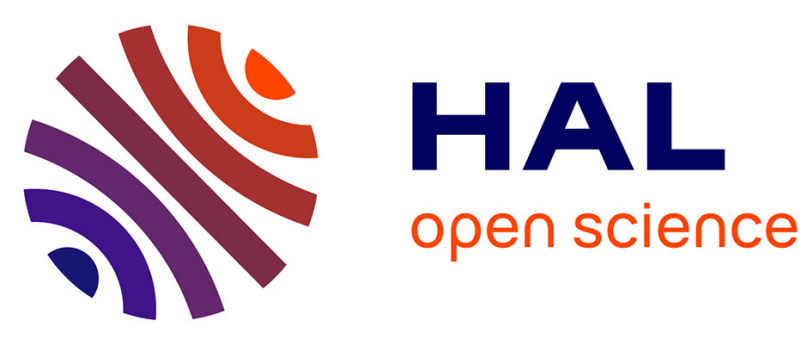

\title{
Diffusion Creep of Diopside
}

Subhajit Ghosh, S. Koizumi, T. Hiraga

\section{To cite this version:}

Subhajit Ghosh, S. Koizumi, T. Hiraga. Diffusion Creep of Diopside. Journal of Geophysical Research :

Solid Earth, 2021, 126 (1), pp.e2020JB019855. 10.1029/2020JB019855 insu-03186366

\section{HAL Id: insu-03186366 \\ https://hal-insu.archives-ouvertes.fr/insu-03186366}

Submitted on 31 Mar 2021

HAL is a multi-disciplinary open access archive for the deposit and dissemination of scientific research documents, whether they are published or not. The documents may come from teaching and research institutions in France or abroad, or from public or private research centers.
L'archive ouverte pluridisciplinaire HAL, est destinée au dépôt et à la diffusion de documents scientifiques de niveau recherche, publiés ou non, émanant des établissements d'enseignement et de recherche français ou étrangers, des laboratoires publics ou privés. 


\section{JGR Solid Earth}

\author{
RESEARCH ARTICLE \\ 10.1029/2020JB019855 \\ Key Points: \\ - Lattice diffusion creep is identified \\ for fine-grained dry diopside \\ aggregate \\ - Flow law parameters for lattice \\ diffusion creep of diopside are \\ determined \\ - Comparison with previous \\ experimental studies in a \\ nondimensional space reveals \\ common creep properties with a \\ small weakening due to $\mathrm{Al}$
}

Correspondence to:

S. Ghosh,

cugeol.subhajit@gmail.com

Citation:

Ghosh, S., Koizumi, S., \& Hiraga, T. (2021). Diffusion creep of diopside. Journal of Geophysical Research: Solid Earth, 126, e2020JB019855. https://doi. org/10.1029/2020JB019855

Received 27 MAR 2020 Accepted 10 DEC 2020
(C) 2020. American Geophysical Union. All Rights Reserved.

\section{Diffusion Creep of Diopside}

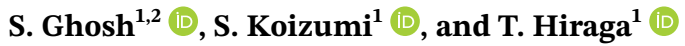 \\ ${ }^{1}$ Earthquake Research Institute, The University of Tokyo, Bunkyo-Ku, Tokyo, Japan, ${ }^{2}$ Institut des Sciences de la Terre \\ d’Orléans (ISTO), UMR 7327, Université d’Orléans, Orléans, France
}

\begin{abstract}
We have conducted uniaxial compression experiments on fine-grained diopside with either 4 or $10 \mathrm{vol} \%$ forsterite and $10 \mathrm{vol} \%$ anorthite. We changed the average grain size in the diopside with forsterite aggregate from 0.43 to $4.07 \mu \mathrm{m}$ to reveal the grain size sensitivity of the creep rate. Mechanical data were obtained at a stepped load for a temperature range of $1050^{\circ} \mathrm{C}-1170^{\circ} \mathrm{C}$. The observed strain rates are best explained by stress and grain size exponent values of 1 and 2, respectively, and activation energy of $\sim 720 \mathrm{~kJ} / \mathrm{mol}$, which indicates lattice diffusion creep. Anorthite bearing aggregate is $\sim 3$ times weaker than forsterite-bearing aggregate, probably due to the presence of aluminum. We have compared previously reported diffusion creep rates of diopside in nondimensional stress and strain-rate space, constructed based on our diffusion creep law. It demonstrates that all the earlier mechanical data are well summarized by our diffusion creep flow law.
\end{abstract}

\section{Introduction}

Diopside, a variety of clinopyroxene is one of the major rock-forming minerals in the lower crust and upper mantle, where deformation occurs by aseismic creep. Several experimental studies focused on establishing flow law of polycrystalline diopside (Bystricky \& Mackwell, 2001; Dimanov \& Dresen, 2005; Dimanov et al., 2007, 2003; Hier-Majumder et al., 2005) based on the equation of

$$
\dot{\epsilon}=A\left(\frac{\sigma^{n}}{d^{p}}\right) \exp \left(-\frac{Q}{\mathrm{R} T}\right)
$$

where, $\dot{\epsilon}$ is the strain rate, $A$ is dimensionless constant, $Q$ is the activation energy for creep, $\mathrm{R}$ is the gas constant, $T$ is absolute temperature, $\sigma$ is the differential stress, $d$ is the grain size, $n$ is stress exponent, and $p$ is the grain size exponent. Theoretical models of the creep have shown different values of $n$ and $p$ for different creep mechanisms. For example, $n=1$ and $p=2$ or 3 indicate lattice diffusion (Nabarro-Herring) creep (Herring, 1950; Nabbaro, 1948) or grain boundary diffusion (Coble) creep (Coble, 1963), respectively. On the other hand, $n \geq 3$ and $p=0$ generally correspond to the dislocation creep process. Earlier experimentally determined flow law parameters of diffusion creep of polycrystalline diopside by different groups (Bystricky \& Mackwell, 2001; Dimanov \& Dresen, 2005; Dimanov et al., 2007, 2003; Hier-Majumder et al., 2005) show many discrepancies. The $Q$ value varies from 364 to $760 \mathrm{~kJ} / \mathrm{mol}$ in addition to large differences in the $A$ value. Variation in composition (e.g., impurity content) in the initial source material can affect the diffusional properties of their diopside samples by altering the point defect concentration and the state of chemical bonding. Furthermore, initial grain-size distribution and the method for grain size measurements are different in the earlier studies, which can generate contrasting results of strength due to grain size sensitivity of diffusion creep (e.g., Hansen et al., 2011). In addition, there are variations in the process of sample preparation (e.g., dry or wet milling, hot-pressing conditions, chemical environment etc.) among different studies.

In order to constrain a robust diffusion creep flow law for diopside, we have carried out high-temperature uniaxial creep experiments (Figure A1) with reagent derived highly dense, fine-grained Fe-free polycrystalline diopside aggregates (+forsterite/anorthite) with homogeneous microstructure. We were able to develop such high-quality samples for rock deformation by mixing high-purity nanosized chemical compounds in appropriate proportion and utilizing vacuum Spark Plasma Sintering (SPS) technique. A comparison between our newly established flow law with previous results from Fe bearing diopside (Bystricky 

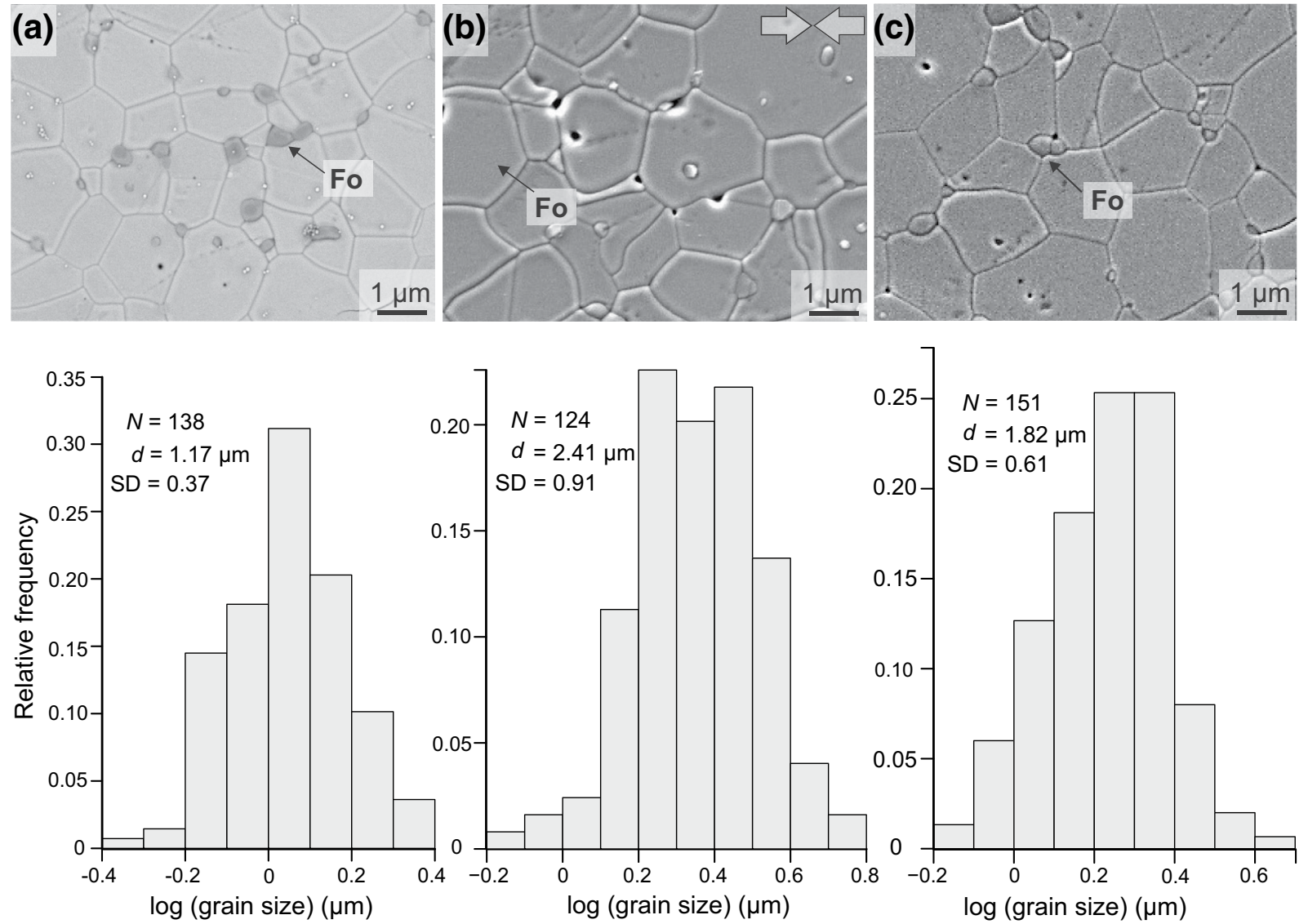

Figure 1. Microstructural observations of diopside $+4 \mathrm{vol} \%$ forsterite aggregates ( $\mathrm{Di}(\mathrm{Fo})$ ) under scanning electron microscope. (a) Secondary electron image clearly distinguishes the secondary forsterite (Fo) grains. Typical homogeneous microstructure is observed in the initial, undeformed aggregate (SP-362). (b) Arrow indicate the compression direction in deformed sample (KG-388). (c) Undeformed reference sample experience the same thermal history as the deformed sample. Homogeneous grain size distribution is observed in the histograms. Average grain sizes are shown.

\& Mackwell, 2001; Dimanov \& Dresen, 2005; Dimanov et al., 2007, 2003; Hier-Majumder et al., 2005) will provide the opportunity to further explore the effects of composition and deformation mechanism on the mechanical properties of diopside aggregates.

\section{Experiments}

\subsection{Materials}

In this study, we synthesized two types of highly dense, fine-grained $(\leq 1 \mu \mathrm{m})$ diopside aggregates (Figures 1 and 2, Figure A2) after the procedures described in Koizumi et al. (2010, 2020): (i) diopside (Di: $\mathrm{CaMgSi}_{2} \mathrm{O}_{6}$ ) mixed with 4 and $10 \mathrm{vol} \%$ of forsterite (Fo: $\mathrm{Mg}_{2} \mathrm{SiO}_{4}$ ) and (ii) diopside mixed with $10 \mathrm{vol} \%$ of anorthite (An: $\mathrm{CaAl}_{2} \mathrm{Si}_{2} \mathrm{O}_{8}$ ). The secondary mineral phases were added to vary the chemical environment and to stabilize the microstructure through grain boundary pinning during the creep tests. Also, the secondary phases help to fix oxide activities in the systems, for example, $\mathrm{MgO}$ activity by forsterite in $\mathrm{Di}$ (Fo) system. We changed the Fo fraction to vary the initial grain size for robust grain size exponent measurement. In the first case, the Di (Fo) aggregate was prepared by mixing nanosized powder of $\mathrm{Mg}(\mathrm{OH})_{2}$ (average particle size of $50 \mathrm{~nm}$, purity of $99.98 \%$ ), colloidal $\mathrm{SiO}_{2}$ (average particle size of $30 \mathrm{~nm}$, purity of $99.9 \%$ ), and $\mathrm{CaCO}_{3}$ in appropriate molar proportion. In the second case, $\mathrm{Di}(\mathrm{An})$ aggregate was developed by mixing $\mathrm{SiO}_{2}, \mathrm{Mg}(\mathrm{OH})_{2}$, $\mathrm{Ca}(\mathrm{OH})_{2}$ (average particle size of $0.1 \mu \mathrm{m}$, purity of $99.9 \%$ ), and $\mathrm{Al}(\mathrm{OH})_{3}$ (average particle size of $0.75 \mu \mathrm{m}$, purity of 99.6\%). Ball milling for $>24 \mathrm{~h}$, using iron-cored plastic balls and high purity ethanol as a solvent was carried out for homogeneous mixing. The slurry was then simultaneously stirred with a magnetic 

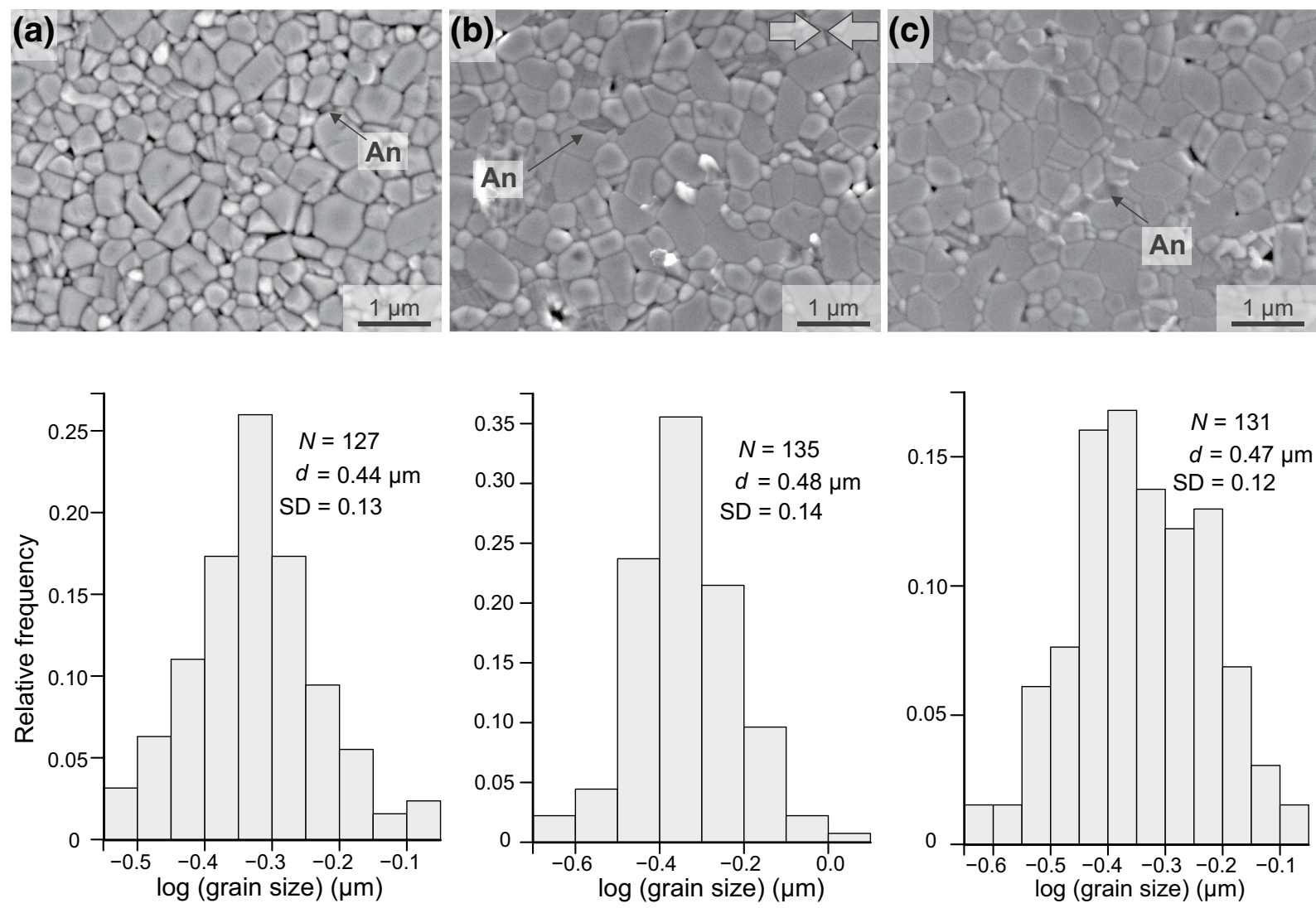

Figure 2. Microstructural observations of diopside $+10 \mathrm{vol} \%$ anorthite aggregates (Di (An)) under scanning electron microscope. (a) Secondary electron image distinguishes the secondary anorthite (An) grains in the initial, undeformed aggregate (SP-497). (b) Arrow indicate the compression direction in deformed sample (KG-395). (c) Undeformed reference sample experiences static grain growth in the same thermal history as the deformed sample. The average grain size in the deformed and reference sample increased. Homogeneous grain size distribution is observed in the histograms.

stirrer and dried at $\sim 60^{\circ} \mathrm{C}$. After drying, the homogeneously mixed powder was calcined at $1040^{\circ} \mathrm{C}$ for $3 \mathrm{~h}$ in an alumina tube furnace under the flow of oxygen to efficiently remove the decomposed by-products like $\mathrm{H}_{2} \mathrm{O}$ and $\mathrm{CO}_{2}$ from the powder. The calcinated material was crushed with an agate mortar and then shaped into the form of a cylinder using a tungsten carbide die. The cylinder-shaped compacts were then wrapped in a vacuumed rubber sleeve and put into water-medium pressure vessel for cold isostatic pressing at $200 \mathrm{MPa}$ for $10 \mathrm{~min}$. The hardened powder pellets were then fitted into a graphite die with a $10 \mathrm{~mm}$ inner diameter in a SPS machine (SPS-110N, Sinterland, Inc., Nagaoka Japan) installed at Earthquake Research Institute, the University of Tokyo. Sintering was performed under vacuum conditions $(\sim 0.4 \mathrm{~Pa})$ at a heating rate of $10^{\circ} \mathrm{C} / \mathrm{min}$ and then held at a temperature of $1210^{\circ} \mathrm{C}$ for $20 \mathrm{~min}$ under a compressive load of $50 \mathrm{MPa}$. After the SPS treatment, the applied pressure was reduced to $<13 \mathrm{MPa}$ and the specimen was subsequently annealed at $1000^{\circ} \mathrm{C}$ for $10 \mathrm{~min}$ to relieve the residual strain. Through this procedure, we obtained a discshaped (10 mm diameter and $3 \mathrm{~mm}$ thickness) specimen, out of which two cuboid samples ( $\sim 6 \mathrm{~mm}$ height, $\sim 3 \mathrm{~mm}$ width and thickness) for creep test were prepared. The remaining fragments were used as reference samples for characterization. SPS is a very efficient method to synthesize fine-grained, dense ( $>99 \%)$ aggregates with little grain growth during sintering (Guignard et al., 2011; Koizumi et al., 2020). In some of our experiments (for example experiment KG-386 in the Table 1), we annealed the sample at a temperature $\geq 50^{\circ} \mathrm{C}$ above the deformation temperature for $3 \mathrm{~h}$ before starting the creep test to diversify the initial grain sizes and inhibit grain growth during the tests through static grain growth process. The sample synthesis process includes solid-state reaction at a temperature lower than the eutectic temperature of Di-An system or the melting temperature of either Di or Fo, which excluded the formation of melt (or glass) at any stage of the synthesis. 
Table 1

Experimental Results of Stepped Load Tests for Di (Fo) Aggregates

\begin{tabular}{|c|c|c|c|c|c|c|c|c|c|c|}
\hline $\begin{array}{l}\text { Experiment } \\
\text { no. }\end{array}$ & $T\left({ }^{\circ} \mathrm{C}\right)$ & $\begin{array}{l}\text { Stress } \\
(\mathrm{MPa})\end{array}$ & $\begin{array}{l}\text { Strain rate } \\
\qquad\left(\mathrm{s}^{-1}\right)\end{array}$ & Strain & $d_{0}(\mu \mathrm{m})$ & $\begin{array}{c}d_{\text {fin }} \\
(\mu \mathrm{m})\end{array}$ & $\begin{array}{c}d_{\text {ref }} \\
(\mu \mathrm{m})\end{array}$ & $d_{\varepsilon}(\mu \mathrm{m})^{\mathrm{a}}$ & $\alpha$ & $\begin{array}{c}k \\
\left(\mu \mathrm{m}^{3} / \mathrm{s}\right)\end{array}$ \\
\hline \multirow[t]{8}{*}{ KG-381 } & \multirow[t]{8}{*}{1100} & 38.5 & $3.92 \mathrm{E}-06$ & 0.04 & \multirow[t]{8}{*}{0.43} & \multirow[t]{8}{*}{0.81} & \multirow[t]{8}{*}{0.69} & 0.49 & \multirow[t]{8}{*}{1.36} & \multirow{8}{*}{$\begin{array}{r}6.68 \mathrm{E}- \\
06\end{array}$} \\
\hline & & 9.5 & 8.09E-07 & 0.04 & & & & 0.59 & & \\
\hline & & 28.4 & $1.85 \mathrm{E}-06$ & 0.05 & & & & 0.65 & & \\
\hline & & 37.6 & 2.09E-06 & 0.06 & & & & 0.69 & & \\
\hline & & 55.5 & 2.92E-06 & 0.08 & & & & 0.72 & & \\
\hline & & 73.1 & 3.67E-06 & 0.09 & & & & 0.75 & & \\
\hline & & 90.2 & $4.04 \mathrm{E}-06$ & 0.10 & & & & 0.78 & & \\
\hline & & 106.9 & 4.54E-06 & 0.11 & & & & 0.81 & & \\
\hline \multirow[t]{6}{*}{ KG-388 } & \multirow[t]{6}{*}{1130} & 75 & $2.75 \mathrm{E}-06$ & 0.06 & \multirow[t]{6}{*}{1.17} & \multirow[t]{6}{*}{2.41} & \multirow[t]{6}{*}{1.82} & 1.55 & \multirow[t]{6}{*}{2.93} & \multirow{6}{*}{$\begin{array}{r}1.00 \mathrm{E}- \\
04\end{array}$} \\
\hline & & 9.3 & $4.56 \mathrm{E}-07$ & 0.06 & & & & 1.80 & & \\
\hline & & 19.9 & $5.92 \mathrm{E}-07$ & 0.07 & & & & 1.95 & & \\
\hline & & 29.7 & $9.43 \mathrm{E}-07$ & 0.08 & & & & 2.06 & & \\
\hline & & 39.3 & $1.28 \mathrm{E}-06$ & 0.08 & & & & 2.13 & & \\
\hline & & 58.3 & $2.01 \mathrm{E}-06$ & 0.09 & & & & 2.22 & & \\
\hline KG-389 ${ }^{b}$ & 1130 & 95.7 & $1.93 \mathrm{E}-05$ & 0.04 & 0.56 & - & - & - & - & - \\
\hline \multirow[t]{12}{*}{ KG-382 } & \multirow[t]{12}{*}{1150} & 38.5 & $1.63 \mathrm{E}-05$ & 0.03 & \multirow[t]{12}{*}{0.43} & \multirow[t]{12}{*}{1.93} & \multirow[t]{12}{*}{1.58} & 0.79 & \multirow[t]{12}{*}{1.35} & \multirow{12}{*}{$\begin{array}{r}1.45 \mathrm{E}- \\
05\end{array}$} \\
\hline & & 9.5 & $3.60 \mathrm{E}-06$ & 0.04 & & & & 0.95 & & \\
\hline & & 28.4 & $8.15 \mathrm{E}-06$ & 0.05 & & & & 1.07 & & \\
\hline & & 37.6 & $8.65 \mathrm{E}-06$ & 0.06 & & & & 1.15 & & \\
\hline & & 55.5 & $1.18 \mathrm{E}-05$ & 0.08 & & & & 1.22 & & \\
\hline & & 73 & $1.31 \mathrm{E}-05$ & 0.09 & & & & 1.27 & & \\
\hline & & 90.2 & $1.49 \mathrm{E}-05$ & 0.10 & & & & 1.32 & & \\
\hline & & 106.8 & $1.61 \mathrm{E}-05$ & 0.11 & & & & 1.38 & & \\
\hline & & 70.5 & $9.92 \mathrm{E}-06$ & 0.12 & & & & 1.43 & & \\
\hline & & 52.5 & 7.03E-06 & 0.13 & & & & 1.49 & & \\
\hline & & 34.7 & $4.63 \mathrm{E}-06$ & 0.14 & & & & 1.59 & & \\
\hline & & 8.6 & $1.08 \mathrm{E}-06$ & 0.14 & & & & 1.81 & & \\
\hline \multirow[t]{10}{*}{ KG-386 } & \multirow[t]{10}{*}{1170} & 98.8 & $6.59 \mathrm{E}-06$ & 0.01 & \multirow[t]{10}{*}{2.11} & 4.07 & 2.84 & 2.51 & 3.62 & $3.23 \mathrm{E}-$ \\
\hline & & 29.4 & $2.01 \mathrm{E}-06$ & 0.01 & & & & 2.60 & & 04 \\
\hline & & 39 & $2.57 \mathrm{E}-06$ & 0.03 & & & & 2.84 & & \\
\hline & & 57.7 & $3.55 \mathrm{E}-06$ & 0.04 & & & & 3.02 & & \\
\hline & & 75.9 & $4.55 \mathrm{E}-06$ & 0.05 & & & & 3.21 & & \\
\hline & & 93.8 & $5.79 \mathrm{E}-06$ & 0.06 & & & & 3.39 & & \\
\hline & & 111.1 & 7.43E-06 & 0.08 & & & & 3.59 & & \\
\hline & & 73.4 & $4.28 \mathrm{E}-06$ & 0.08 & & & & 3.70 & & \\
\hline & & 54.6 & $2.52 \mathrm{E}-06$ & 0.09 & & & & 3.90 & & \\
\hline & & 36.2 & $1.41 \mathrm{E}-06$ & 0.10 & & & & 4.05 & & \\
\hline KG-390 & 1170 & 93.9 & $6.30 \mathrm{E}-05$ & 0.05 & 0.56 & 1.16 & - & 0.56 & - & - \\
\hline & & 25.4 & 1.33E-05 & 0.16 & & & & 1.16 & & \\
\hline
\end{tabular}

${ }^{a}$ Estimated grain size based on dynamic grain growth law. ${ }^{\mathrm{b}} \mathrm{Di}$ aggregate with $10 \mathrm{vol} \%$ Fo. 


\subsection{Deformation Tests}

Our creep experiments were performed in a uniaxial compression apparatus (Autograph AG-X) (Appen$\operatorname{dix}$ A) with an integrated furnace under non controlled atmosphere conditions (free air) (Figure A1). The axial force was measured by a highly sensitive load cell directly attached to the loading rod, while displacement was measured at the crosshead of the apparatus. All our mechanical, that is, force-displacement data were obtained at a stepped load (i.e., applying multiple stresses) for a constant temperature. We collected force-displacement-time data every second. Our load measurement is accurate within $\pm 0.4 \%$ of the applied force and displacement rates are within $\pm 0.1 \%$ of the set speed (Nakakoji et al., 2018). The compressive force data were converted to differential stresses by assuming a change in area with uniform compression and constant sample volume. The stresses measured during our tests ranged from 10 to $120 \mathrm{MPa}$. Similarly, the strain was determined from the crosshead displacement considering the subsequent sample lengths at any given moment during the experiments as $\epsilon=-\ln \left(\frac{h}{h_{0}}\right)$, where $\varepsilon$ is true strain, $h_{0}$ is the initial sample height, and $h$ is the instantaneous sample height at each step during the creep test. Average strain rates $(\dot{\epsilon})$ and stresses $(\sigma)$ were obtained, where we could assume steady-state creep.

Before starting an experiment, one rectangular sample was placed between a pair of $\mathrm{SiC}(\phi=25 \times 16 \mathrm{~mm}$ thick) and alumina discs $(\phi=25 \times 4 \mathrm{~mm})$ over the $\mathrm{SiC}$ piston rod $(\phi=40 \mathrm{~mm})$. No reaction between the discs and the sample was detected. The temperature during an experiment was measured by a R-type thermocouple (Pt and Pt-Rh), located next to the sample (Figure A1). In addition, we kept a small piece of the same starting sample just adjacent to the rectangular sample, which would experience an identical thermal condition in the central hot zone of the furnace as our deformed sample. Hereafter, we will refer to this undeformed, annealed sample as the reference sample and the mean grain size calculated from this as the reference grain size $\left(d_{\text {ref }}\right)$.

In order to estimate the grain sizes at any time during an experiment (i.e., $d_{\epsilon}$ ), we used the combined static and dynamic grain growth law (Holm et al., 1977; Nakakoji et al., 2018; Tasaka \& Hiraga, 2013):

$$
d_{\epsilon}=\left(k t+d_{0}^{m}\right)^{1 / m} \cdot \exp (\alpha \epsilon)
$$

where, $t$ is the duration of grain growth, $\epsilon$ is the strain, $d_{0}$ is initial grain size, and $m$ is the grain growth exponent, which is assumed to be 3 . The $m=3$ value corresponds to the theoretical value for lattice diffusion controlled static grain growth (Lifshitz \& Slyozov, 1961; Wagner, 1961). As shown in Nakakoji and Hiraga (2018), a common diffusional mechanism for creep and grain growth in polymineralic system is expected. We will show later in the text that lattice diffusion is the dominant mechanism for diffusion creep in diopside and thus, supports lattice diffusion-controlled grain growth for our diopside aggregate. The dynamic grain growth constant, $\alpha=\frac{1}{\epsilon} \ln \frac{d_{\text {fin }}}{d_{\text {ref }}}$ is calculated as a function of the ratio between the final deformed $\left(d_{\text {fin }}\right)$ and reference $\left(d_{\text {ref }}\right)$ grain sizes. The grain growth coefficient $(k)$ under static conditions is calculated as, $k=\left(d_{\text {ref }}^{m}-d_{0}^{m}\right) / t$. For our stepped-load tests at a constant temperature, we adjusted the $\alpha$ and $k$ terms to incorporate the observed values of $d_{0}, d_{\text {ref }}$, and $d_{\text {fin }}$ in the Equation 2 (Tables 1 and 2).

\subsection{Sample Characterizations}

Fabricated mineral powders were analyzed by X-ray fluorescence (ZSX Primus (II), Rigaku Japan), revealing that all trace element concentrations were less than $10 \mathrm{ppm}$. Phase identification of the sintered aggregates were conducted using X-ray diffraction (SmartLab; RIGAKU Japan). We observed diopside peaks, while the peaks from forsterite and anorthite were absent probably due to their small fractions in the aggregates. The deformed samples were cut through the center, parallel to the compression direction. All the sections were finally polished with colloidal silica. Subsequently, they were thermally etched to expose the grain boundaries, at a temperature range of $1000^{\circ} \mathrm{C}-1100^{\circ} \mathrm{C}$ for $30 \mathrm{~min}$ in the air, which was $\sim 100^{\circ} \mathrm{C}$ less than the deformation or sintering temperatures. It ensures negligible grain growth during thermal etching. In order to observe the microstructures and determine the average grain sizes, all the samples were examined under a scanning electron microscope (SEM) equipped with a field emission gun (JEOL 7001F) 
Table 2

Experimental Results of Stepped Load Tests for Di (An) Aggregates

\begin{tabular}{|c|c|c|c|c|c|c|c|c|c|c|}
\hline $\begin{array}{l}\text { Experiment } \\
\text { no. }\end{array}$ & $T\left({ }^{\circ} \mathrm{C}\right)$ & $\begin{array}{l}\text { Stress } \\
(\mathrm{MPa})\end{array}$ & $\begin{array}{l}\text { Strain rate } \\
\qquad\left(\mathrm{s}^{-1}\right)\end{array}$ & Strain & $d_{0}(\mu \mathrm{m})$ & $\begin{array}{c}d_{\text {fin }} \\
(\mu \mathrm{m})\end{array}$ & $\begin{array}{c}d_{\text {ref }} \\
(\mu \mathrm{m})\end{array}$ & $d_{\varepsilon}(\mu \mathrm{m})^{\mathrm{a}}$ & $\alpha$ & $\begin{array}{c}k \\
\left(\mu \mathrm{m}^{3} / \mathrm{s}\right)\end{array}$ \\
\hline \multirow[t]{7}{*}{ KG-395 } & \multirow[t]{7}{*}{1050} & 38.9 & $2.10 \mathrm{E}-06$ & 0.03 & \multirow[t]{7}{*}{0.44} & \multirow[t]{7}{*}{0.48} & \multirow[t]{7}{*}{0.47} & 0.45 & \multirow[t]{7}{*}{0.21} & \multirow{7}{*}{$\begin{array}{r}4.25 \mathrm{E}- \\
07\end{array}$} \\
\hline & & 29.7 & $1.49 \mathrm{E}-06$ & 0.03 & & & & 0.46 & & \\
\hline & & 48.9 & $1.57 \mathrm{E}-06$ & 0.05 & & & & 0.46 & & \\
\hline & & 58.2 & $1.76 \mathrm{E}-06$ & 0.06 & & & & 0.47 & & \\
\hline & & 76.4 & 2.03E-06 & 0.07 & & & & 0.47 & & \\
\hline & & 94.3 & $2.34 \mathrm{E}-06$ & 0.09 & & & & 0.48 & & \\
\hline & & 111.8 & $2.69 \mathrm{E}-06$ & 0.10 & & & & 0.48 & & \\
\hline \multirow[t]{10}{*}{ KG-396 } & \multirow[t]{10}{*}{1100} & 38.4 & $2.34 \mathrm{E}-05$ & 0.04 & \multirow[t]{10}{*}{0.44} & \multirow[t]{10}{*}{0.51} & \multirow[t]{10}{*}{0.48} & 0.46 & \multirow[t]{10}{*}{0.38} & \multirow{10}{*}{$\begin{array}{r}4.25 \mathrm{E}- \\
06\end{array}$} \\
\hline & & 18.9 & $1.14 \mathrm{E}-05$ & 0.04 & & & & 0.46 & & \\
\hline & & 28.3 & $1.74 \mathrm{E}-05$ & 0.05 & & & & 0.47 & & \\
\hline & & 37.3 & $2.00 \mathrm{E}-05$ & 0.07 & & & & 0.47 & & \\
\hline & & 55.1 & $2.72 \mathrm{E}-05$ & 0.08 & & & & 0.48 & & \\
\hline & & 72.2 & 3.07E-05 & 0.10 & & & & 0.49 & & \\
\hline & & 88.7 & $3.46 \mathrm{E}-05$ & 0.11 & & & & 0.49 & & \\
\hline & & 70.4 & $2.83 \mathrm{E}-05$ & 0.12 & & & & 0.49 & & \\
\hline & & 52.3 & $2.22 \mathrm{E}-05$ & 0.13 & & & & 0.50 & & \\
\hline & & 34.5 & $1.78 \mathrm{E}-05$ & 0.14 & & & & 0.51 & & \\
\hline \multirow[t]{10}{*}{ KG-394 } & \multirow[t]{10}{*}{1150} & 38.4 & $9.99 \mathrm{E}-05$ & 0.03 & \multirow[t]{10}{*}{0.48} & \multirow[t]{10}{*}{0.62} & \multirow[t]{10}{*}{0.55} & 0.54 & \multirow[t]{10}{*}{0.65} & \multirow[t]{10}{*}{$8.2 \mathrm{E}-06$} \\
\hline & & 9.2 & $2.33 \mathrm{E}-05$ & 0.04 & & & & 0.55 & & \\
\hline & & 27.8 & $7.48 \mathrm{E}-05$ & 0.05 & & & & 0.56 & & \\
\hline & & 36.7 & $8.96 \mathrm{E}-05$ & 0.06 & & & & 0.56 & & \\
\hline & & 54.7 & $1.11 \mathrm{E}-04$ & 0.08 & & & & 0.57 & & \\
\hline & & 71.6 & $1.27 \mathrm{E}-04$ & 0.10 & & & & 0.58 & & \\
\hline & & 67.4 & $1.13 \mathrm{E}-04$ & 0.14 & & & & 0.60 & & \\
\hline & & 50 & $9.38 \mathrm{E}-05$ & 0.15 & & & & 0.61 & & \\
\hline & & 32.6 & 7.23E-05 & 0.16 & & & & 0.61 & & \\
\hline & & 15.8 & $3.82 \mathrm{E}-05$ & 0.17 & & & & 0.62 & & \\
\hline
\end{tabular}

${ }^{\mathrm{a}}$ Estimated grain size based on dynamic grain growth law.

at Nano-Manufacturing Institute, The University of Tokyo. Additionally, transmission electron microscopy (TEM) was carried out to observe the microstructure and the occurrence of any melt at the grain boundaries and triple junctions (Appendix B). We conducted the deformation experiments as well as the aggregate syntheses under dry conditions, so that the aggregates had little chance of incorporating water. We confirmed the "dry" state of the aggregates using Fourier transform infrared spectroscopy (FT-IR) (Appendix C; Figure A3). We used the freely available "Image J" (NIH) software to carry out the grain size analysis from the SEI images. The two-dimensional (2D) cross-sectional area $(a)$ of each grain was approximated to the diameter $(d=2 \sqrt{a / \pi})$ of an equivalent circle (Ghosh et al., 2016). More than 100 measurements $(N)$ were used for calculating the arithmetic mean $(d)$ of the grain size population for each sample (Figures 1 and 2).

\section{Results}

\subsection{Microstructural Observations}

Our initial, deformed and the reference Di (Fo) and Di (An) samples (Figures 1 and 2) were characterized by: (i) <1vol\% porosity, (ii) mostly equiaxed grains with foam texture, although some of the diopside grains 
(a)

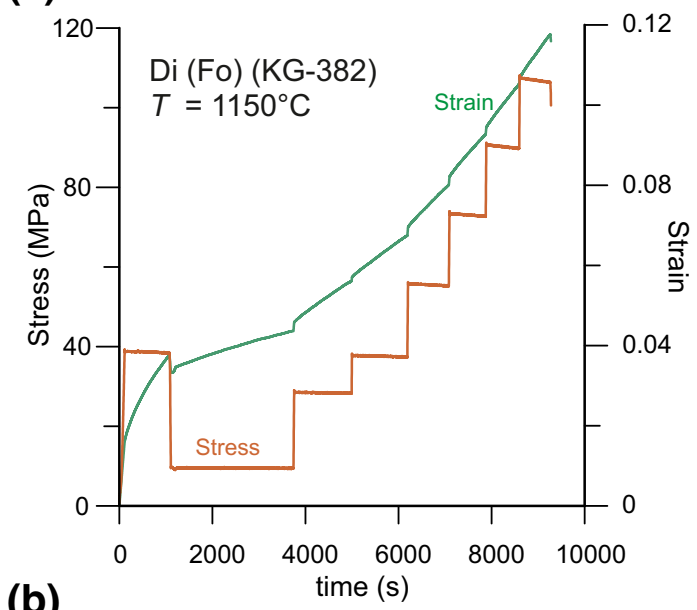

(b)

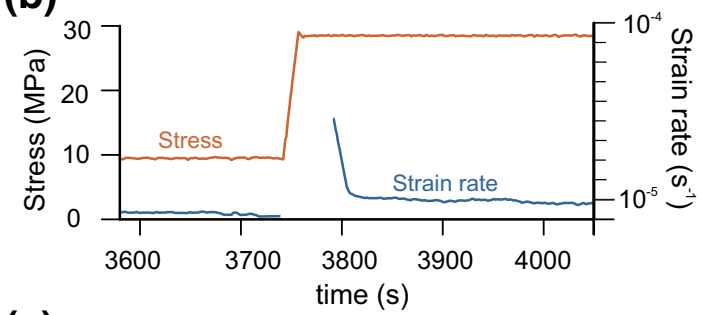

(c)

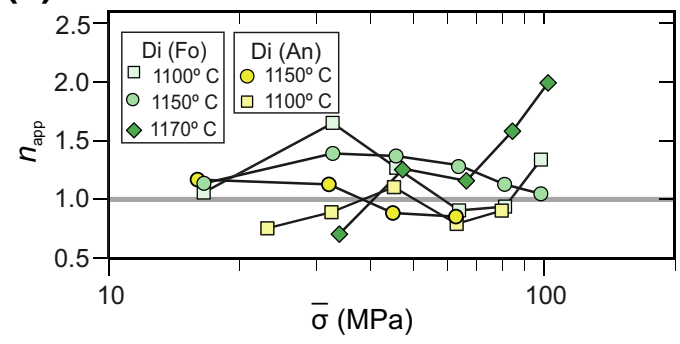

Figure 3. Experimental creep data. (a) A typical rheological data obtained during stepped experiment at $1150^{\circ} \mathrm{C}(\mathrm{KG}-382)$. (b) Stress/strain rate versus time curves during a particular load step (KG-382). (c) The apparent stress exponent, $n_{\text {app }}$ is calculated from two sets of stress and strain rate values as $n_{\text {app }}=\frac{\log \dot{\epsilon}_{i+1}-\log \dot{\epsilon}_{i}}{\log \sigma_{i+1}-\log \sigma_{i}}$ versus the geometric average stress, $\bar{\sigma}\left(=\sqrt{\sigma_{i} \sigma_{i+1}}\right)$. Different shades of green colors indicate Di (Fo) data (KG381, 382, 386), while yellow colors indicate Di (An) data (KG-396, 394). in Di (An) aggregates had a tabular, anisotropic shape with long straight grain boundaries (Figure 2a), (iii) homogeneously distributed secondary phases at the intergranular spaces of diopside grains, and (iv) primary diopside phase with visibly coarser grain size. The resultant microstructure shows a log-normal grain size distribution (Figures 1 and 2). The final average grain sizes in the deformed samples $\left(d_{\text {fin }}\right)$ were larger than the reference samples $\left(d_{\text {ref }}\right)$, as both these values were increased from the initial grain size $\left(d_{0}\right)$ (Tables 1 and 2). Mechanochemical polishing with colloidal silica for $15 \mathrm{~min}$ is sufficient to observe large intergranular melt pockets (glass) by their distinct lower dihedral angle $\left(<60^{\circ}\right)$. In addition, TEM analysis confirms that our samples are melt free at $5 \mathrm{~nm}$ resolution (Figure A4). Individual grains are also essentially dislocation free.

\subsection{Mechanical Data}

Stress/strain versus time data were obtained at a stepped load test for a temperature range of $1050^{\circ} \mathrm{C}-1170^{\circ} \mathrm{C}$. A typical stepped-load test at a constant temperature (e.g. experiment $\mathrm{KG}-382$ at $1150^{\circ} \mathrm{C}$ ) is presented in Figure 3a. The slope of the strain curve increases with increasing load on the sample. Small but ubiquitous strain hardening is observed for each load step, which is attributed to the continuous grain growth under grain size sensitive creep. To investigate the stress sensitivity of strain rate on minimizing the grain growth effect, the value of the apparent stress exponent $\left(n_{\text {app }}\right)$ between two successive stress-steps is explored (Nakakoji et al., 2018). Each $\dot{\epsilon}$ is calculated from $\varepsilon$ achieved for a time gap, for example $50 \mathrm{~s}$ in Figure $3 \mathrm{~b}$. For $n_{\text {app }}$, we need two sets of $\left(\sigma_{i}, \dot{\epsilon}_{i}\right)$ and $\left(\sigma_{i+1}\right.$, $\left.\dot{\epsilon}_{i+1}\right)$ data, which were obtained just before and after changing the loads, respectively (Figure $3 \mathrm{~b}$ ):

$$
n_{\text {app }}=\frac{\log \dot{\epsilon}_{i+1}-\log \dot{\epsilon_{i}}}{\log \sigma_{i+1}-\log \sigma_{i}}
$$

The time window between $\left(\sigma_{i}, \dot{\epsilon_{i}}\right)$ and $\left(\sigma_{i+1}, \dot{\epsilon}_{i+1}\right)$ is small enough to eliminate the grain growth effects on the extracted stress exponent, while we lose accuracy on the $n$ value. It is to be noted that we used the stabilized values of $\sigma_{i+1}$ and $\dot{\epsilon}_{i+1}$ after changing the load (Figure 3b). We see a rapid increase of $\dot{\epsilon}$, which is resulted due to a rapid increase in the applied $\sigma$ (i.e., load). The $\dot{\epsilon}$ is then decreases significantly and becomes stabilized after $\sim 3,700$ s. This stabilized $\dot{\epsilon}_{i+1}$ and the $\dot{\epsilon}_{i}$ measured just before changing the load are used for analyses (i.e., $7.9 \times 10^{-6}$ and $2.3 \times 10^{-6} \mathrm{~s}^{-1}$, respectively). We expect the $n_{\text {app }}$ values to detect the changes in the stress exponent with stress. The $n_{\text {app }}$ is plotted against the geometric mean stress, $\bar{\sigma}\left(=\sqrt{\sigma_{i} \sigma_{i+1}}\right)$ (Figure 3c). Overall, most of the $n_{\text {app }}$ indicates a value of $1 \pm 0.5$, without any systematic changes with increasing stress, which implies grain size sensitive Newtonian creep at all stress conditions.

Since the $n_{\text {app }}$ results indicate diffusion creep with stress independent viscosity, the grain size dependency of the stain rate is examined by plotting the inverse of viscosity $(\eta=\sigma / \dot{\epsilon})$ against the grain size (Figure 4a). We used the grain sizes that were measured under a SEM (Table 1), in addition to the estimated sizes during the experiments. The transparent symbols in Figure 4a are the estimated grain sizes at each stress step, based on Equation 2. This procedure produces a reliable grain size exponent $(p)$ by minimizing the error associated with microstructural evolution with time, that is, the estimated grain sizes $\left(d_{\varepsilon}\right)$ plot within the limit of observed $d_{0}$ and $d_{\mathrm{fin}}$. We wanted to incorporate a large variation in grain sizes to determine a robust grain size exponent. Therefore, we combined the experimental results of 4 and 10 vol\% (KG-389 and KG390) forsterite (Table 1). We assumed that there was no effect of minor change in forsterite fraction on the 
(a)
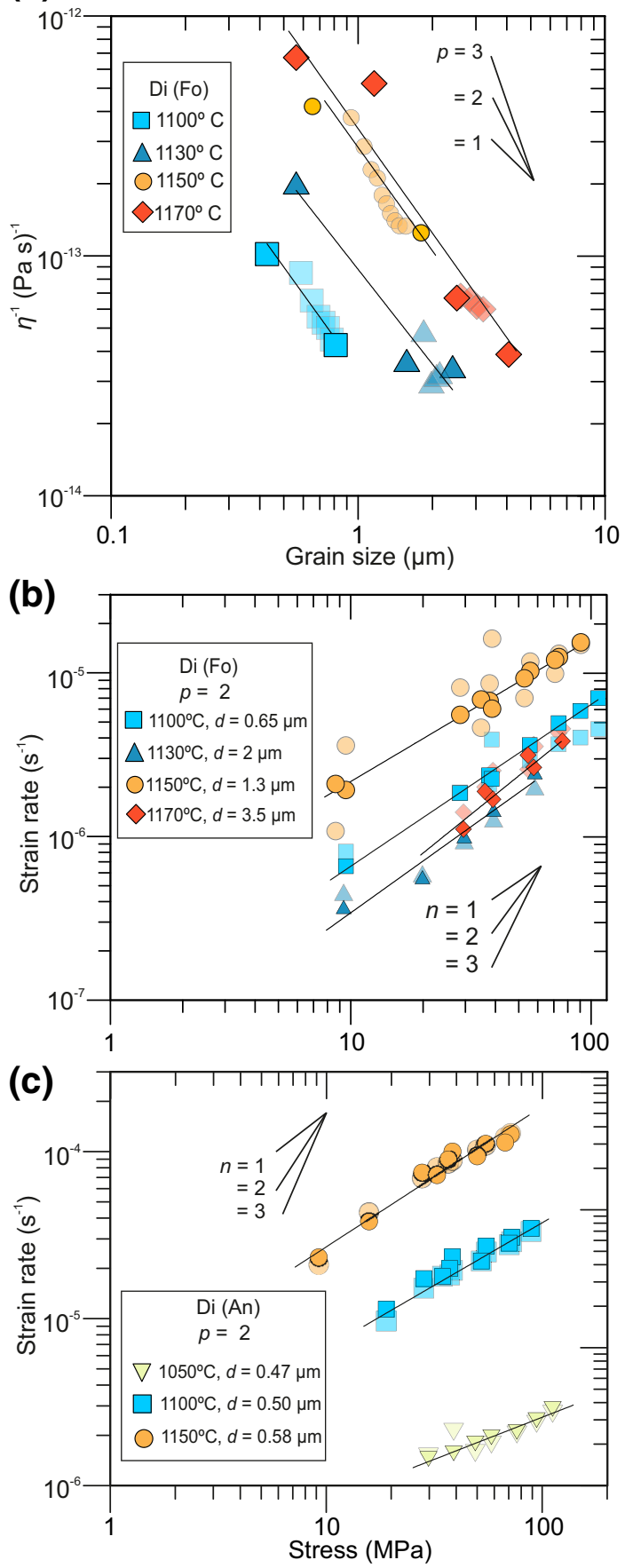

Figure 4. Determination of flow law parameters like Grain size exponent $(p)$ and stress exponent $(n)$ in a log-log space. (a) Plots of grain size versus inverse of viscosity $\left(\eta^{-1}\right)$ for a temperature range of $1100^{\circ} \mathrm{C}-1170^{\circ} \mathrm{C}$. (b and c) Plots of stress versus strain rate with fixed $d$, using $p=2$. Transparent symbols are the original mechanical data, correspond to the same solid color symbols. Best fit lines for solid symbols are shown in the figure. creep properties of diopside. This assumption is reasonable as the secondary phases remained dispersed and isolated in the aggregate during the deformation (Figures 1 and 2). Such a microstructure ensures that the bulk strength of the aggregate was controlled by the primary phase (Nakakoji \& Hiraga, 2018). A negative correlation is found from the slope of the global fit (Figure 4a). The data with large grain size variation from $\sim 0.4$ to $4 \mu \mathrm{m}$ for $\mathrm{Di}$ (Fo) aggregate at $1170^{\circ} \mathrm{C}$ are well fitted with $p$ of $\sim 2$, which is also applicable for fitting the data at different temperatures.

As the $p$ value of $\sim 2$ is consistent with the theoretical model for lattice diffusion creep (Herring, 1950; Nabarro, 1948), the stress dependency is revaluated by normalizing the strain rates to a particular grain size, using a fixed grain size exponent of $p=2$ (Figures $4 \mathrm{~b}$ and $4 \mathrm{c}$ ). The uncorrected data are also added in such plotting. Although the corrections do not alter the strain rate much, we observe a better fit with stress exponent, $n=1 \pm 0.1$ (Figures $4 \mathrm{~b}$ and $4 \mathrm{c}$ ), which is consistent with the conclusion from the $n_{\text {app }}$ values (Figure 3c).

Since we concluded $n=1$ and $p=2$ above, we plot all the $\eta^{-1}$ values ( $\eta=\sigma / \dot{\epsilon}$ ) in Arrhenius space, where $\dot{\epsilon}$ is calibrated to a grain size of $1 \mu \mathrm{m}$ using $p=2$. The $\eta^{-1}$ values vary by a factor of 2 at the same temperatures (Figure 5). It supports our analysis of the temperature dependency of the strain rate in this manner. Moreover, the similar slope of the global fit indicates that the $\eta^{-1}$ values of $\mathrm{Di}$ (Fo) and $\mathrm{Di}(\mathrm{An})$ are well fitted with the single Arrhenius equation with similar values of activation energy (i.e., $Q=720 \pm 70 \mathrm{~kJ} / \mathrm{mol}$ ) (Figure 5). However, the creep rates for Di (An) aggregate are $\sim 3$ times faster than Di (Fo) aggregate. We will show later in the Section 4.3.3 that this $Q$ is also well suited for fitting earlier experimental results.

\section{Discussion}

\subsection{Deformation Mechanism and Constitutive Equation}

We found that the values of $n=1$ and $p=2$ (Equation 1) explain our mechanical data well (Figure 4), as expected from lattice diffusion creep models (Herring, 1950; Nabbaro, 1948). Although the $p$ value was not extracted from the data of $\mathrm{Di}(\mathrm{An})$ aggregate, but essentially the same $Q$ values under Newtonian creep for both Di (Fo) and Di (An) aggregates support the operation of the same deformation mechanism (Figure 5). Since Di (Fo) and Di (An) aggregates were fine-grained, we initially predicted to identify grain boundary diffusion creep, based on our earlier olivine diffusion creep results (Nakakoji et al., 2018; Yabe \& Hiraga, 2020; Yabe et al., 2020). However, none of our data support $p=3$ (Figure 4a). We once obtained a $p$ value of $\sim 2$ along with $n$ of $\sim 1.5$ (at $\sigma$ in a range of $\sim 10-\sim 150 \mathrm{MPa}$ and $T$ of $\left.1260^{\circ} \mathrm{C}-1360^{\circ} \mathrm{C}\right)$ in fine-grained $(\sim 1 \mu \mathrm{m})$ enstatite-bearing (from 0 to 50 vol\%) Fe-free olivine aggregates (Tasaka et al., 2013), which was subsequently explained as the consequence of a transition from interface-controlled creep to grain boundary diffusion creep (Nakakoji \& Hiraga, 2018; Nakakoji et al., 2018). Later, we showed the presence of interface-controlled creep $(p=1)$ at lower stress $(<20 \mathrm{MPa})$ condition than the condition for diffusion creep specifically from olivine +20 vol\% enstatite (Nakakoji et al., 2018). Grain-boundary dislocations are commonly assumed in the models of power-law interface-controlled creep with $n=2$ or 3 and $p=1$ (Arzt et al., 1983; Ashby, 1969; Burton, 1972; Yabe et al., 2020). In the present study, the operation of the power-law interface-controlled creep in diopside is not supported from the $n_{\text {app }}$ results (Figures $3 \mathrm{c}, 4 \mathrm{~b}$, 


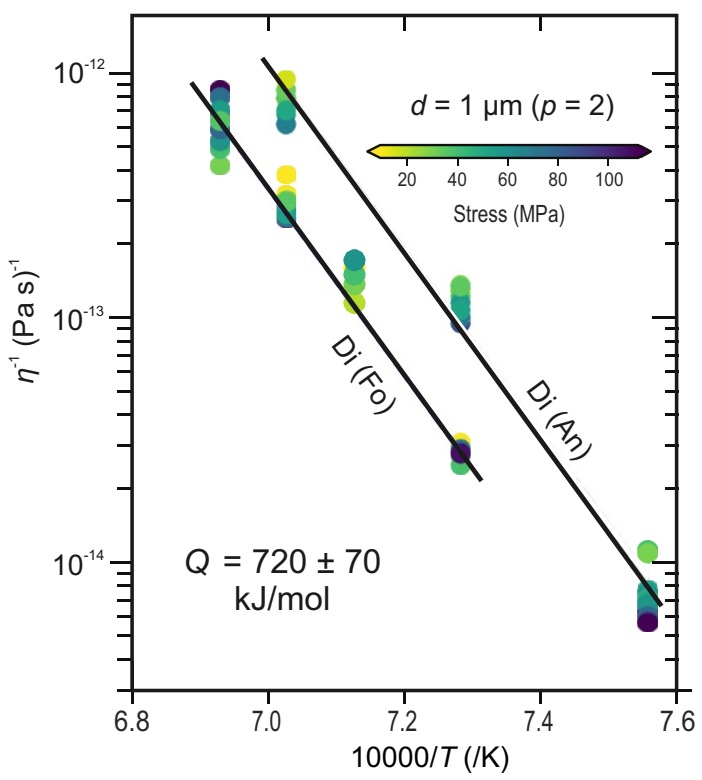

Figure 5. Arrhenius plots of inverse of viscosity $\left(\eta^{-1}\right)$ with fixed $d$ $(=1 \mu \mathrm{m})$ and $p(=2)$ against $10000 / T$ for $\mathrm{Di}(\mathrm{Fo})$ and $\mathrm{Di}(\mathrm{An})$ aggregates. Different color symbols indicate corresponding stress values. and 4c). Consequently, we conclude lattice diffusion creep for the diopside in this study. Providing the $Q$ value reported in Table 3 to Equation 1, we obtained the preexponential term, $A$ of $8.01 \times 10^{19} \mu \mathrm{m}^{2} / \mathrm{MPa} / \mathrm{sec}$ for $\mathrm{Di}$ (Fo) samples. Thus, the flow law for Di (Fo) is as follows,

$$
\dot{\varepsilon}_{\text {diff }}=8.01 \times 10_{\mu \mathrm{m}^{2} / M P a / s e c}^{19} \cdot\left(\sigma / d^{2}\right) \cdot \exp \left(-\frac{720 \mathrm{~kJ} / \mathrm{mol}}{\mathrm{R} T}\right)
$$

Since both of our diopside samples in the Arrhenius plot (Figure 5) have the same activation energy, the difference in strength ( $\sim 3$ times) between $\mathrm{Di}(\mathrm{Fo})$ and $\mathrm{Di}(\mathrm{An})$ is explained by the difference in the $A$ value. Therefore, we propose that the $A$ value for $\mathrm{Di}(\mathrm{An})$, which is larger by a factor of $\sim 3$ relative to the value for Di (Fo) (Figure 5), might be explained by increasing point defect due to $\mathrm{Al}$ dissolution into diopside. $\mathrm{Al}$ in diopside can increase the number of Si vacancy with the charge neutrality condition $\left[\mathrm{Al}_{\mathrm{Si}}^{\prime}\right]=4\left[\mathrm{~V}_{\mathrm{Si}}^{\prime \prime \prime}\right]$.

\subsection{Compositional Self-Diffusion Model of Creep}

We compare our results with creep rates predicted from the self-diffusivity of constituent ions of diopside. The reported diffusivities (usually the slowest one) correspond to $D_{\text {latt }}$ that constitutes lattice diffusion creep law (Fei et al., 2016; Frost \& Ashby, 1982; Herring, 1950; Nabbaro, 1948; Weertman, 1999) of the following form:

$\dot{\epsilon}_{\text {latt }}($ Nabarro - Herring $)=A^{\prime} \sigma \frac{\beta D_{\text {latt }} V_{m}}{d^{2} \mathrm{R} T}$

Here, $A^{\prime}(=150 / \pi)$ is a constant in the classic model of diffusion creep (Burton, 1977; Coble, 1963; Herring, 1950; Nabbaro, 1948). It is known that the $A^{\prime}$ value from the classical diffusion creep models (Coble, 1963; Herring, 1950; Nabbaro, 1948) underestimates the actual creep rate $\left(\dot{\epsilon}_{\text {latt }}\right)$ by a factor of $\sim 10$ due to diffusion accommodated grain boundary sliding rather than by conventional diffusion creep (Wang, 2000). In order to acquire a reasonable value of $\dot{\epsilon}_{\text {latt }}$, the $A^{\prime}$ value is multiplied by 10 , which has been confirmed for olivine (Nakakoji \& Hiraga, 2018). Since the original solution was developed for 3D grain sizes, we normalized $(150 / \pi) \times 10$ by $1.77^{2}$ so that the Equation 5 holds for $2 \mathrm{D}$ grain sizes.

In the case of silicate minerals, silicon ( $\mathrm{Si}$ ) is generally considered to be the slowest constituent ion for both the grain boundary and lattice diffusion (Dohmen et al., 2002). Therefore, we can compare our diffusion creep results with the strain rates predicted from Si self-diffusion $\left(D_{\mathrm{Si} \_l a t t}\right)$ in diopside (Béjina \& Jaoul, 1996). We used the molar volume, $V_{m}$ of $\mathrm{Si}$ as $3.31 \times 10^{-5} \mathrm{~m}^{3} / \mathrm{mol}$ for diopside (Holland \& Powell, 2011). We have introduced a coefficient $\beta$ in Equation 5, which accounts for a compound effect on self-diffusivity during creep i.e. $D_{\text {latt_creep }}$ and relate it to the self-diffusivity of each constituent elements of diopside (i.e., $D_{\text {Ca_latt }}$, $D_{\text {Mg_latt }}, D_{\text {Si_latt }}$, and $\left.D_{\text {O_latt }}\right)$ as

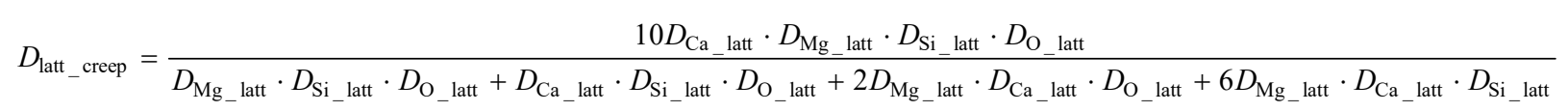

Equation 6 has to hold to maintain stoichiometry and charge neutrality of diopside during diffusion creep. When $D_{\mathrm{Si}_{-} \text {latt }} \ll D_{\mathrm{O}_{-} \text {latt }}, D_{\mathrm{Ca} \_ \text {latt }}$ and $D_{\mathrm{Mg} \_ \text {latt }}$ in Equation 6 , then $D_{\text {latt_creep }}$ can be approximated by $D_{\mathrm{Si} \_ \text {latt }}$ as

$$
D_{\text {latt_creep }} \approx(10 / 2) D_{\mathrm{Si}_{-} \text {latt }}
$$

Hence, from stoichiometric consideration, the value of $\beta$ is 5 for Si self-diffusion in diopside (CaMg$\mathrm{Si}_{2} \mathrm{O}_{6}$ ). The results are plotted in Figure 6, which shows $\dot{\epsilon}_{\text {latt }}$ is significantly underestimating the actual strain rate $(\dot{\epsilon})$. It is possible that dominant diffusion paths, that is, either grain boundary or lattice, are different for different constituent ions. In that case, Si diffusion at grain boundaries and lattice diffusion 
Table 3

Rheological Flow Law of Diopside

\begin{tabular}{lllllc}
\hline & \multicolumn{1}{c}{$A$} & & & \multicolumn{2}{l}{$\frac{Q}{2}$} \\
\cline { 2 - 3 } Sample & $\mu \mathrm{m}^{p} / \mathrm{MPa} / \mathrm{sec}$ & & & $P$ & $\mathrm{~kJ} / \mathrm{mol}$ \\
\hline $\mathrm{Di}(\mathrm{Fo})$ & $8.01 \times 10^{19}$ & & 1 & 2 \\
\hline
\end{tabular}

of the second slowest ion can occur, which might be responsible for the observed creep rates. Therefore, we examined the contribution of calcium $(\mathrm{Ca})$ and oxygen (O) self-diffusivity on $\dot{\epsilon}$ following the values reported in Dimanov and Ingrin (1995) and Ingrin et al. (2001). Although faster than Si self-diffusivity, both $\mathrm{Ca}$ and $\mathrm{O}$ are also underestimating the actual $\dot{\epsilon}$ (Figure 6). It is also necessary to note that the activation energies measured from natural single crystal of diopside for $\mathrm{Si}, \mathrm{Ca}$, and $\mathrm{O}$ self-diffusion from experiments carried out at the similar temperature range as our creep experiments (Béjina \& Jaoul, 1996; Dimanov \& Ingrin, 1995; Ingrin et al., 2001) are much lower (211-280 kJ/mol) compare to the $Q$ value for creep. Thus, it remains difficult to interpret the lattice diffusion in diopside in terms of the known self-diffusivity values of either $\mathrm{Si}, \mathrm{Ca}$, or $\mathrm{O}$.

\subsection{Comparison With Previous Studies}

We compare our newly established diffusion creep law for diopside (Equation 4) with the results from previous studies (Bystricky \& Mackwell, 2001; Dimanov \& Dresen, 2005; Dimanov et al., 2003; Hier-Majumder et al., 2005) in a nondimensional space (Nakakoji et al., 2018). This method differs from using flow law parameters to calibrate mechanical data obtained from various grain sizes, temperatures, stress, and so on under certain conditions. Previously, we have demonstrated its utility in comparing mechanical data of olivine from various research groups (Yabe \& Hiraga, 2020; Yabe et al., 2020).

\subsubsection{Stress and Strain Rate Relationships}

The original mechanical ( $\sigma$ and $\dot{\epsilon}$ ) data from the earlier studies are transformed to nondimensional stress $\left(\sigma_{0}\right)$ and strain rate $\left(\dot{\epsilon}_{0}\right)$ ratios, using $\left(\sigma^{* \text { ref }}, \dot{\epsilon}^{* \text { ref }}\right)$ :

$$
\sigma_{0}=\frac{\sigma}{\sigma^{* \mathrm{ref}}} \text { and } \dot{\epsilon_{0}}=\frac{\dot{\epsilon}}{\dot{\epsilon}^{* \text { ref }}}
$$

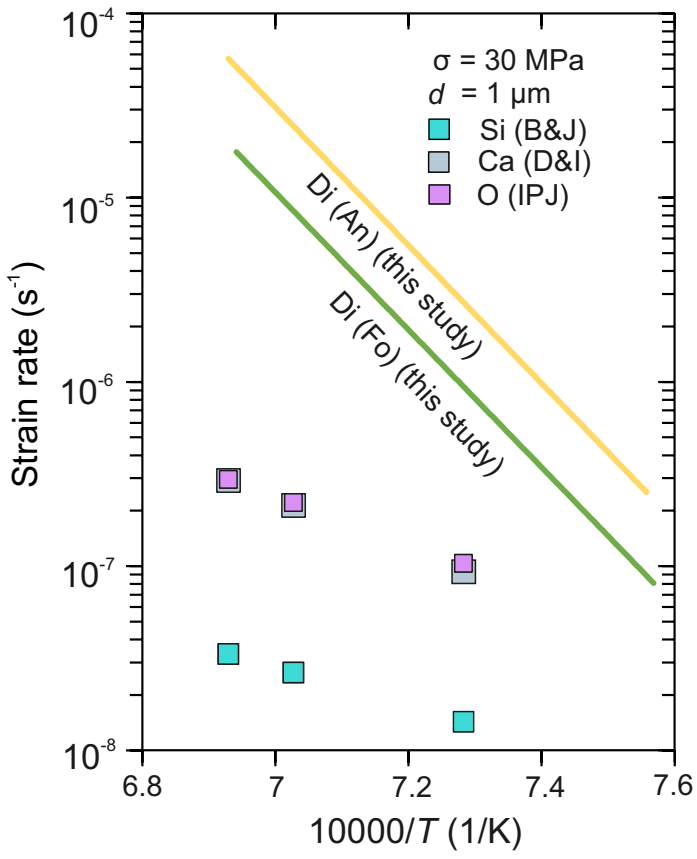

Figure 6. Arrhenius plot of lattice diffusion creep rates for Di (An) and $\mathrm{Di}(\mathrm{Fo})$ aggregates. The yellow and green lines are calculated from Equation 4 using the flow law parameters determined in this study. Square symbols are calculated based on Equation 5 and the measured lattice self-diffusivities of Si (Béjina \& Jaoul, 1997) (B\&J), Ca (Dimanov \& Ingrin, 1995) (D\&I), and O (Ingrin et al., 2001) (IPJ), respectively.
Here, the reference strain rate $\left(\dot{\epsilon}^{* \text { ref }}\right)$ is calculated from our Di (Fo) flow law parameters (Table 3 ) by substituting the $d$ and $T$ values at which each original $\sigma$ and $\dot{\epsilon}$ was acquired to Equation 1 . We use a fixed value of $10 \mathrm{MPa}$ for $\sigma^{* \text { ref }}$ in this case. The Di (Fo) mechanical data plots along the reference line in the Figure 7a, which demonstrates the ability of Equation 4 to express the original mechanical data. All the data show a Newtonian-like relationship, which supports the comparison of earlier diffusion creep data in this manner. Clearly, the wet diopside data (Hier-Majumder et al., 2005) are 2-3 orders of magnitude weaker than dry diopside data (Figure 7a). Except for Hier-Majumder et al. (2005) (we refer HM hereafter), most of the dry data fall very close to either our Di (Fo) or Di (An) results.

\subsubsection{Grain Size Dependency}

Here, we compare the effect of grain size from the previous studies on the viscosity ( $\sim$ creep rates) in the nondimensional $\eta_{0}^{-1}$ versus $d_{0}$ space. First, the original mechanical ( $\sigma$ and $\dot{\epsilon}$ ) data are used to calculate the inverse of viscosity $\left(\eta^{-1}\right)\left(\mathrm{Pa} \mathrm{s}^{-1}\right)$. Then, the $\eta^{-1}$ data are transformed into a nondimensional inverse viscosity $\left(\eta_{0}^{-1}\right)$ and grain size $\left(d_{0}\right)$ ratios, using $\left(\left(\eta^{* \text { ref }}\right)^{-1}, d^{* \text { ref }}\right)$ :

$$
\eta_{0}^{-1}=\frac{\eta^{-1}}{\left(\eta^{*}\right)^{\text {ref }}} \text { and } d_{0}=\frac{d}{d^{* \mathrm{ref}}}
$$




\section{(a)}

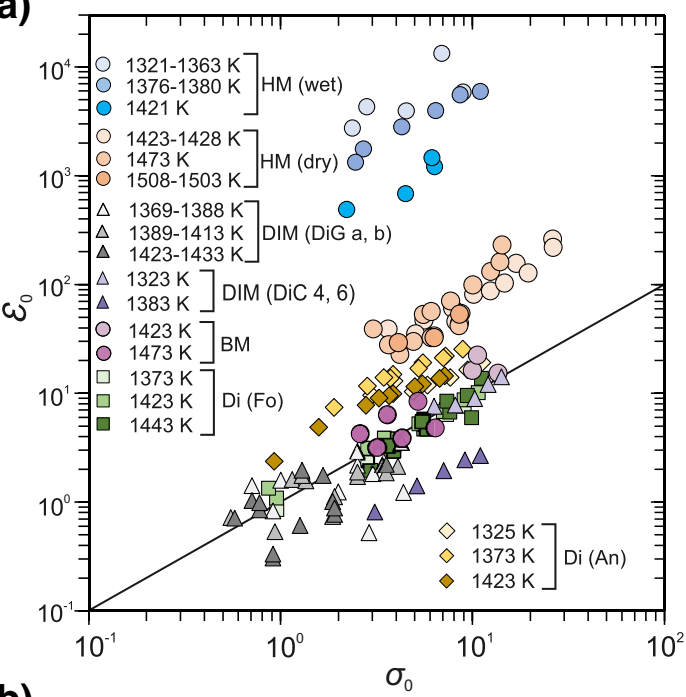

(b)

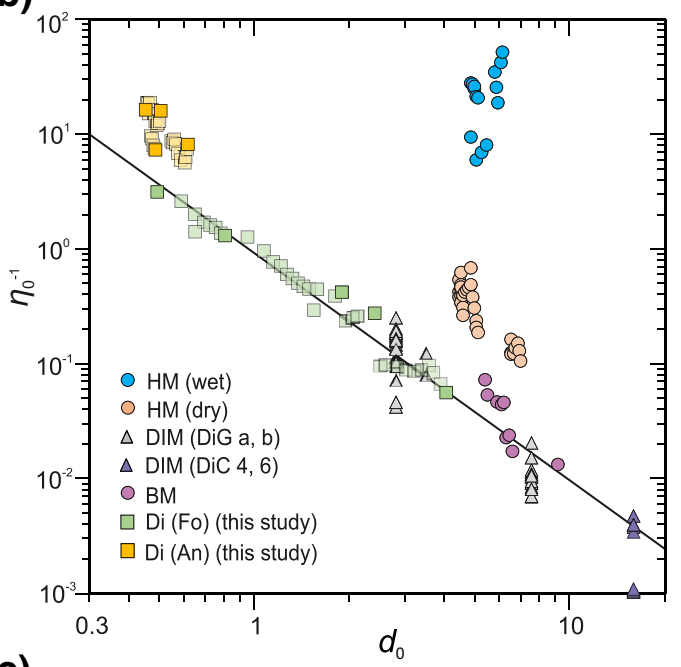

(c)

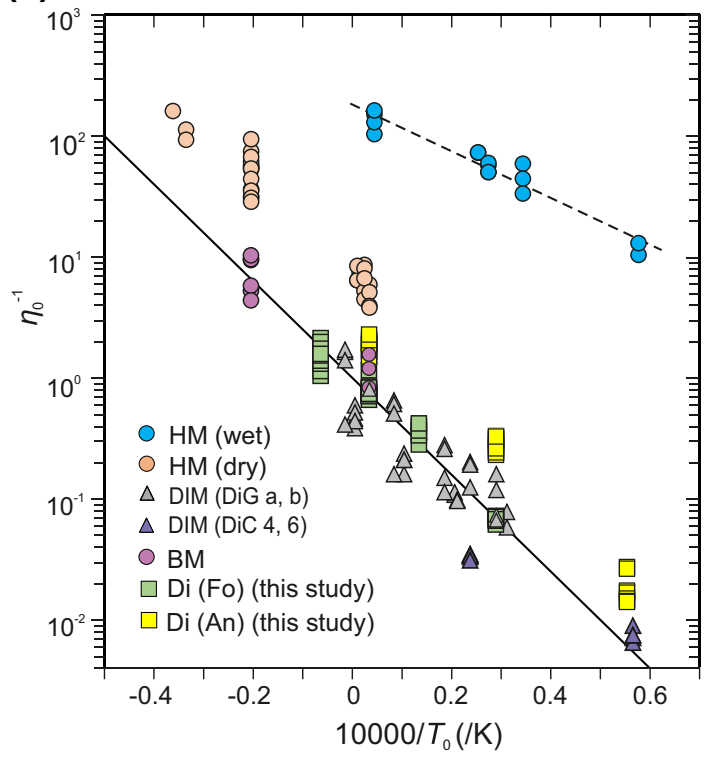


Here, the reference inverse viscosity $\left(\left(\eta^{* \text { ref }}\right)^{-1}\right)$ is calculated from our Di (Fo) flow law parameters (Table 3) by substituting the original $\sigma$ and $T$ values to Equation 1 . We use a fixed grain size of $1 \mu \mathrm{m}$ for $d^{* \text { ref }}$. The results are plotted in Figure 7b. We observe that our Di (Fo) mechanical data in the range of an order of magnitude are following the reference line. It is clearly seen from this plotting that some of the earlier studies (Bystricky \& Mackwell, 2001; Hier-Majumder et al., 2005) did not have sufficient grain size resolution to support their $p$ value. Taking into account of the scattering in the plots, only the data of Dimanov et al. (2003) (we refer DIM hereafter), which include both Fe-bearing natural diopside single crystal powder (DiC 4, 6) and Fe-free synthetic diopside glass samples (DiG a, b) allow extracting grain size dependency. Although DIM concluded the $p$ value as 3, it seems that the value of 2 can explain their synthetic diopside mechanical data and complement our Di (Fo) data at the larger grain-size range (Figure 7b). In fact, DIM proposed the $p$ value based on analysis of pure diopside end-member product like ours using synthetic diopside glass samples. Unfortunately, it is difficult to recognize each of those data from their table. Therefore, our analysis of DIM data is limited to their accessible data, which leads to a different conclusion on the $p$ value (Figure 7b). Similar to DIM, HM also preferred $p=3$, assuming grain boundary diffusion creep. Considering their limited grain size range and scatter (Figure $7 \mathrm{~b}$ ), we have to judge their data for determining the $p$ value as inadequate. Not only the result of DIM and HM but also the results from Bystricky and Mackwell (2001) (we refer BM hereafter) can be satisfactorily described by the $p$ value of 2 determined in this study.

\subsubsection{Temperature Dependency}

In Figure $7 \mathrm{c}$, we compare the normalized inverse of viscosity $\left(\eta_{0}^{-1}\right)$ and the inverse of temperature $\left(T_{0}^{-1}\right)$ in the Arrhenius space to understand the effect of temperature on the viscosity ( $\sim$ creep rates). In this case, the original $\eta^{-1}\left(\mathrm{~Pa} \mathrm{~s}^{-1}\right)$ data are transformed into a nondimensional inverse viscosity $\left(\eta_{0}^{-1}\right)$ ratio and inverse temperature $\left(\frac{10000}{T_{0}}\right)$, using $\left(\left(\eta^{* \text { ref }}\right)^{-1}, T^{* \text { ref }}\right)$ by:
\[ \eta_{0}^{-1}=\frac{\eta^{-1}}{\left(\eta^{*}{ }^{\text {ref }}\right)^{-1}} \text { and } \frac{10000}{T_{0}}=\frac{10000}{T}-\frac{10000}{T^{*} \text { ref }} \]

Again, the reference inverse viscosity $\left(\left(\eta^{* \text { ref }}\right)^{-1}\right)$ is calculated from our Di (Fo) flow law parameters (Table 3) by substituting the original $\sigma$ and $d$ values in the Equation 1 . The temperature $(T)$ is substituted by $T^{* \text { ref }}$, which is $1420 \mathrm{~K}$. It should be noticed that in this plot $\left(\frac{10000}{T_{0}}\right)$ is not a dimensionless number. We can observe that the Di (Fo) mechanical data are following the reference line in Figure 7c, while Di (An) and HM data runs almost parallel to it. Therefore, it is likely that the $Q$ of $760 \mathrm{~kJ} / \mathrm{mol}$ reported by $\mathrm{HM}$ is quite reasonable and remain within the error of our $\mathrm{Di}$ (Fo) $Q$ value (Table 3). However, it is surprising to find a similar temperature dependency from BM and DIM data, although they reported a lower $Q$ value of $\sim 560 \mathrm{~kJ} / \mathrm{mol}$, using samples of different chemical composition. It is likely that the treatment of the original mechanical data assuming grain boundary diffusion and large error associated with measured grain sizes (DIM) or lack of data points (BM) leads to a lesser estimate. Furthermore, as expected, the lower slope for the diopside diffusion creep data (HM-wet) in the water-saturated condition indicate a much lower activation energy is needed for diffusion creep under such a condition.

\subsubsection{Summary}

In line with the above discussion, we can summarize all the previously obtained experimental results from different groups based on similar strain rate dependencies on stress, grain size, and temperature

Figure 7. Comparisons of our newly established diffusion creep law for Di (Fo) (Equation 4) with the results of previous studies in nondimensional and seminondimensional spaces. (a) Plot of nondimensionalized strain rate $\left(\dot{\epsilon}_{0}\right)$ as a function of nondimensionalized stress $\left(\sigma_{0}\right)$ calculated from the original mechanical data $(\sigma$ and $\dot{\epsilon})$. (b) Plot of nondimensionalized inverse viscosity $\left(\eta_{0}^{-1}\right)$ as a function of nondimensionalized grain size $\left(d_{0}\right)$. (c) Nondimensionalized inverse $\operatorname{viscosity~}\left(\eta_{0}^{-1}\right)$ as a function of inverse temperature $\left(T_{0}^{-1}\right)\left(\frac{10000}{T_{0}}=\frac{10000}{T}-\frac{10000}{T^{*} \text { ref }}\right)$. 


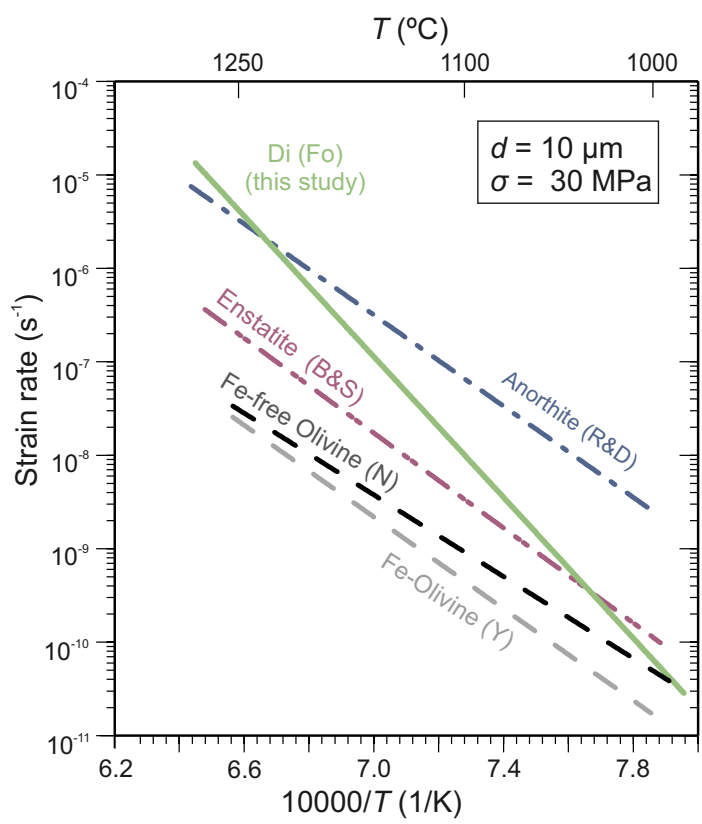

Figure 8. Arrhenius plot of strain rate as a function of $10000 / T$ of dry diopside (this study), Fe-olivine (Yabe \& Hiraga, 2020; Yabe et al., 2020) (Y), Fe-free olivine (Nakakoji et al., 2018) (N), enstatite (Bruijn \& Skemer, 2014) (B\&S), and anorthite (Rybacki \& Dresen, 2000) (R\&D) in the diffusion creep regime are shown. All the plots are fixed to $d=10 \mu \mathrm{m}$ and $\sigma=30 \mathrm{MPa}$. as our mechanical data. It is indicative of the operation of the same underlying creep mechanism, that is, lattice diffusion creep in this case. Even the absolute strengths are essentially comparable except for the HM data. Hansen et al. (2011) have observed that the olivine grain size measurements by optical microscope (on thick sections etched with acid) from older studies (e.g., Hirth \& Kohlstedt, 2003) are yielding grain sizes that are larger by a factor of 2, than the measurements by high-resolution SEM and electron back scattered diffraction. Consequently, the strain rates were overestimated by a factor of at least $2^{3}$ in the earlier studies of olivine grain boundary diffusion creep (N. Zhao et al., 2019). Noteworthily, the same research group provided the experimental results of the HM, using the optical microscopy to measure grain sizes. Therefore, we consider that the same correction should be made for the HM data. Given that the true grain sizes in HM are finer than their reported values by a factor of 2, the creep rates of HM are all systematically decreased by a factor of $2^{2}$ (Figure 7a). Such corrections result in essentially the same strengths reported by BM. It should be noticed that both $\mathrm{BM}$ and $\mathrm{HM}$ used the same source powder from Fe-bearing Sleaford Bay clinopyroxenite $\left(\mathrm{Ca}_{0.97} \mathrm{Mg}_{0.78} \mathrm{Fe}_{0.26} \mathrm{Si}_{1.99} \mathrm{O}_{6}\right)$ to prepare their experimental aggregates and utilized the same gas apparatus for the deformation experiments. Hence, we conclude that the results of $\mathrm{HM}$ and BM are basically same.

The Fe-free synthetic glass sample (DiG a, b) used by DIM basically follows our Di (Fo) data along the reference line (Figure 7). The scattering observed in their data can result from the large errors associated with their average grain sizes due to bimodal grain size distribution. On the other hand, their Fe-bearing diopside single crystal powder ( $\mathrm{DiC} 4,6)$ with composition of $\mathrm{Ca}_{0.969} \mathrm{Na}_{0.025} \mathrm{~K}_{0.001} \mathrm{Mg}_{0.970} \mathrm{Fe}_{0.036} \mathrm{Cr}_{0.130} \mathrm{Al}_{0.007} \mathrm{Mn}_{0.001}$ $\mathrm{Ni}_{0.001} \mathrm{Si}_{0.986} \mathrm{O}_{6}$ plots close to our reference lines (Figure 7). Fe is often attributed to the source of point defects in silicate minerals (Chakraborty, 1997; Y. H. Zhao et al., 2009) by changing its valence state, and hence, affects creep rate. However, the similar creep strengths of synthetic Fe-free aggregates in comparison to the naturally derived Fe-bearing aggregates show that Fe has no significant effect in controlling the rate of diopside diffusion creep. DIC samples at a temperature $1383 \mathrm{~K}$ are little stronger than our samples. Again, it highlights our conclusion regarding the effect of Fe. Earlier, we have reached the same conclusion for fine-grained olivine, where Fe-free and Fe-bearing olivine show the same creep rates by grain boundary diffusion (Tasaka et al., 2013; Yabe et al., 2020). The source material of HM, BM, and DIM had some trace amount of Al. Overall, the absolute strength of Ca-bearing clinopyroxene during diffusion creep is well summarized by Equation 4, after incorporating small weakening effect due to Al.

The $Q$ value determined in this study is higher than its typical value for silicate minerals $(300-600 \mathrm{~kJ} /$ mol) (Bruijn \& Skemer, 2014; Nakakoji et al., 2018; Rybacki \& Dresen, 2000). It is interesting to note that such a high $Q$ value is comparable to the high activation energy reported for dislocation creep (760 \pm 40 to $719 \pm 34 \mathrm{~kJ} / \mathrm{mol}$ ) in diopside (Bystricky \& Mackwell, 2001; Dimanov et al., 2003). The dislocation creep is rate controlled by diffusion in the lattice (i.e., climb-control), such that essentially the same $Q$ value for lattice diffusion and dislocation creep is well supported from the micro-processes of both the creep mechanisms. However, as discussed earlier, we cannot define the creep rates based on self-diffusivities of any particular constituent elements (Figure 6), which remain to be solved in future studies.

\subsection{Comparisons With Other Minerals}

The strength of the different geomaterials undergoing diffusion creep in dry condition, like Fe-bearing olivine (Yabe et al., 2020), Fe-free olivine (Nakakoji et al., 2018), anorthite (Rybacki \& Dresen, 2000), orthopyroxene (Bruijn \& Skemer, 2014), and clinopyroxene (i.e., diopside) (this study) are compared in the Arrhenius plot (Figure 8). The olivine experiments were carried out using reagent derived samples from 
our lab, while anorthite polycrystalline aggregates were prepared from crushed anorthite glass (Rybacki $\&$ Dresen, 2000). All the strain rates used in the comparison were normalized to a two-dimensional grain size of $10 \mu \mathrm{m}$. Figure 8 reveals that our diopside samples are substantially weaker than Fe-olivine/Fe-free olivine and orthopyroxene considering an upper mantle shear zone $\left(>1050^{\circ} \mathrm{C}, d=10 \mu \mathrm{m}\right)$. On the other hand, the general occurrence of pyroxene porphyroclasts with fully recrystallized olivine in many mantle shear zone rocks indicate that olivine is much weaker than pyroxene in grain-size insensitive dislocation creep regime (Hidas et al., 2013; Skemer et al., 2010; Toy et al., 2010; Warren \& Hirth, 2006; and references therein) and consequently, controls the overall rheology. However, a switch in the deformation mechanism to grain-size sensitive creep leading to rheological weakening is often envisaged in natural shear zones (Hidas et al., 2013; Toy et al., 2010; Warren \& Hirth, 2006), where diopside diffusion creep rheology may exert significant control. Although, diopside is harder than both anorthite and olivine in the lower crustal condition $\left(>900^{\circ} \mathrm{C}\right)$, but under hydrous environment diopside aggregates show considerable weakening (Figure 7a).

\section{Conclusions}

In the past decade, there are several attempts to understand the diffusion creep behavior of Ca-bearing clinopyroxene, that is, diopside due to its importance in understanding the bulk strength of the dry lower crust and upper mantle, using experimental rock deformation (Bystricky \& Mackwell, 2001; Dimanov \& Dresen, 2005; Dimanov et al., 2007, 2003; Hier-Majumder et al., 2005). In contrast to the earlier diffusion creep studies on diopside, our experiments yield a fundamentally different result in terms of underlying deformation mechanism as lattice diffusion $(n=1$ and $p=2)$. Moreover, our diopside flow law can satisfactorily explain all the original mechanical data from earlier studies and highlights a minor weakening effect due to aluminum (Al), while it seems Fe does not provide any significant effect in controlling the thermally activated diffusion creep process in the diopside. Furthermore, under certain low stress-strain rate upper mantle conditions, the diopside is considerably weaker than olivine and orthopyroxene, where the grain size sensitive diffusion creep can dominate.

\section{Appendix A: Deformation Apparatus}

Our creep experiments were performed using the same uniaxial deformation testing apparatus (Shimadzu AG-X) with a furnace attached as Nakakoji et al. (2018), installed at the Earthquake Research Institute, University of Tokyo. We collected force-displacement-time data every second. The compressional force was measured by a load cell directly attached to the loading rod, and displacement was measured at the crosshead of the apparatus. The load cell measures the force directly applied to the sample without any intervening dissipating forces, such as friction.

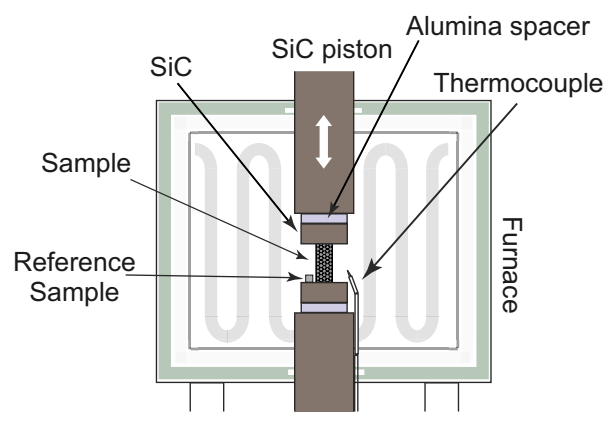

Figure A1. Schematic diagram (modified after Nakakoji et al. [2018]) of uniaxial deformation apparatus for creep experiments with a box furnace attachment is shown. 


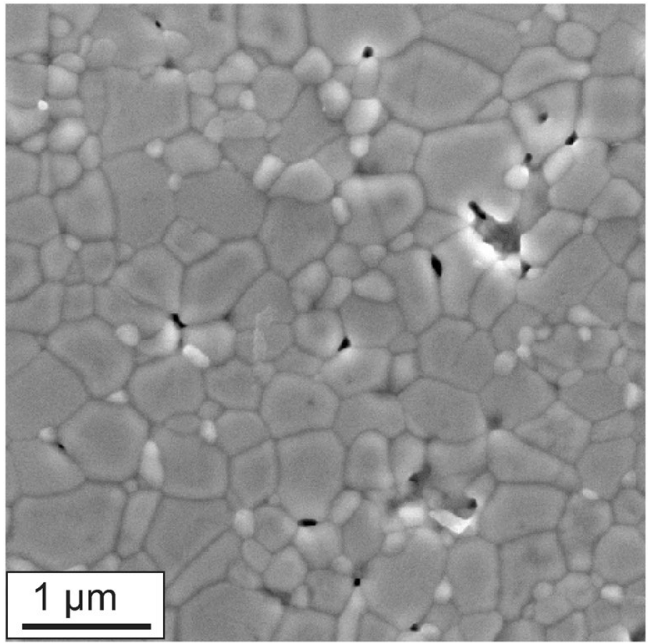

Figure A2. Microstructural observations of diopside $+10 \mathrm{vol} \%$ forsterite aggregates (Di (Fo)), using SEM. Typical homogeneous microstructure is observed in the initial, undeformed aggregate (SP-408). SEM, scanning electron microscope.

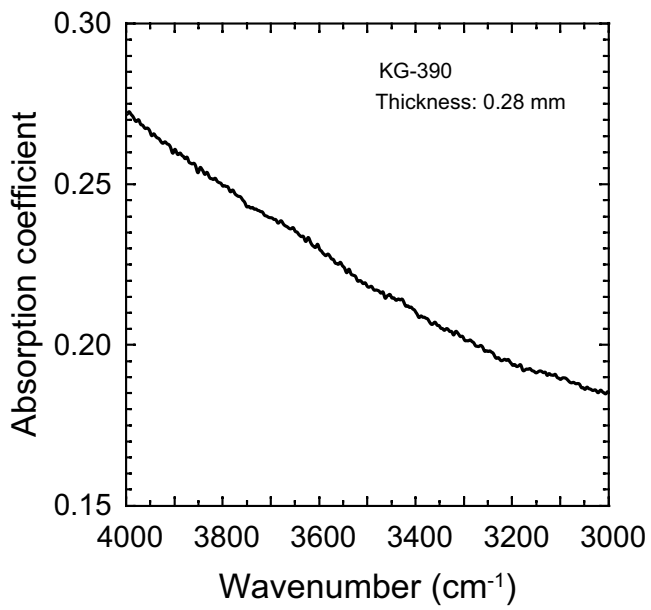

Figure A3. FT-IR spectrum (without background correction) from the deformed Di +10 vol\% Fo aggregate (KG-390). The specimen thickness is $280 \mu \mathrm{m}$. FT-IR, Fourier transform infrared spectroscopy. 

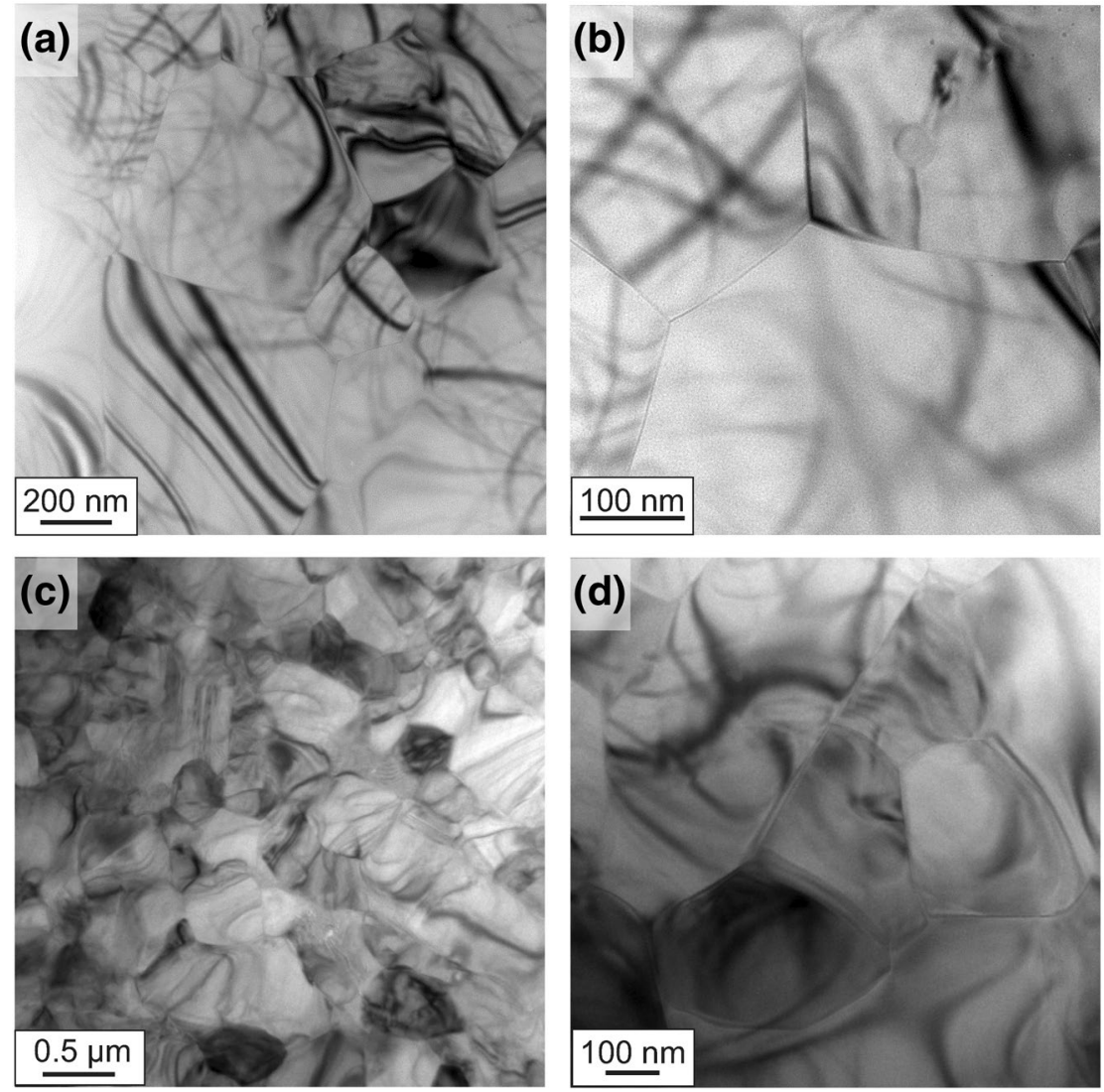

Figure A4. Microstructural observations under transmission electron microscopy (TEM). (a and b) TEM observations of deformed Di $+10 \mathrm{vol} \%$ Fo aggregate (KG-390) is shown. At the scale of observation, the grain boundaries and the triple junctions are devoid of any melt and the individual grains are also essentially dislocation free. (c and d) TEM observations of deformed Di +10 vol\% An aggregate (Di (An)) (KG-394) is shown. Similar to the Di (Fo) samples, our Di (An) samples are melt-free at the scale of observation. Few dislocations and pores can be seen.

\section{Appendix B: Transmission Electron Microscopy}

We used transmission electron microscopy (TEM) to observe microstructures and the occurrence of any melt from selected aggregates of deformed Di (Fo) (KG-390) and Di (An) (KG-394) samples. An ion slicer was utilized to prepare thin foils for TEM. Both sides of the thin samples were coated with carbon to prevent charging during TEM observations. We did not apply any etching techniques to the samples. The observations were carried out on a $200 \mathrm{kV}$ electron microscope (JEM-2010F) installed at Nano-Manufacturing Institute, University of Tokyo.

\section{Appendix C: FT-IR Analyses}

We used a system composed of a JASCO FT/IR-660 Plus spectrometer and a JASCO IRT-30 microscope, installed at the Earthquake Research Institute at the University of Tokyo. The entire beam path was evacuated to less than a few tens of Pascal using a rotary vacuum pump, which minimized the noise absorption from atmospheric $\mathrm{CO}_{2}$ and $\mathrm{H}_{2} \mathrm{O}$ (Yasuda, 2014). The spectra were collected between wave numbers $400-7,800 \mathrm{~cm}^{-1}$ (resolution of $4 \mathrm{~cm}^{-1}$ ) at the room temperature. We analyzed $280 \mu \mathrm{m}$ thick samples using an aperture of $100 \times 100 \mu \mathrm{m}$; thus, the number of grains generating the observed absorption is on the order of $10^{6}$ in each sample. Absence of $\mathrm{OH}$ absorption peaks at 3,625, 3,540, 3,460, and 3,355 $(1 / \mathrm{cm})$ known for diopside (Bell et al., 1995; Peslier et al., 2002) indicate that there is no water present in our sample. 


\section{Data Availability Statement}

All the experimental results are given in the Tables 1 and 2 and are available in Zenodo (http://doi. org/10.5281/zenodo.3975477).

Acknowledgments

S. Ghosh acknowledges the International Research Promotion Office of the Earthquake Research Institute, The University of Tokyo for the Visiting Post-doc Invitation Program and supporting this study. We are grateful to K. Yabe and A. Yasuda for the FT-IR analysis. This study would not be possible without the help of A. Okamoto, H. Yamauchi, A. Takeuchi, S. Ohtsuka, and N. Kim. S. Ghosh is thankful to A. Laik for color coding the Figure 5. We thank G. Dresen, A. Dimanov, and A. Tommasi for their constructive reviews. We are also thankful to Yves Bernabe and Qin Wang for handling this manuscript. A portion of this work was conducted at the Center for Nano Lithography \& Analysis of the University of Tokyo, supported by the Ministry of Education, Culture, Sports, Science and Technology (MEXT), Japan (Grant Number JPMXP09A19UT0014). This study was supported by the JSPS through Grant-in-Aid for Scientific Research 18H03734, 15H05827, Earthquake Research Institute's cooperative research program to $\mathrm{T}$. Hiraga and by the JSPS through Grant-in-Aid for Scientific Research 18K03799 to S. Koizumi.

\section{References}

Arzt, E., Ashby, M. F., \& Verrall, R. A. (1983). Interface controlled diffusional creep. Acta Metallurgica, 31(12), $1977-1989$. Ashby, M. F. (1969). On interface-reaction control of Nabarro-Herring creep and sintering. Scripta Metallurgica, 3(11), 837-842.

Béjina, F., \& Jaoul, O. (1996). Silicon self-diffusion in quartz and diopside measured by nuclear micro-analysis methods. Physics of the Earth and Planetary Interiors, 97(1-4), 145-162. https://doi.org/10.1016/0031-9201(96)03137-8

Bell, D. R., Ihinger, P. D., \& Rossman, G. R. (1995). Quantitative analysis of trace OH in garnet and pyroxenes. American Mineralogist, $80(5-6), 465-474$

Bruijn, R. H., \& Skemer, P. (2014). Grain-size sensitive rheology of orthopyroxene. Geophysical Research Letters, 41(14), 4894-4903. https:// doi.org/10.1002/2014GL060607

Burton, B. (1972). Interface reaction controlled diffusional creep: A consideration of grain boundary dislocation climb sources. Materials Science and Engineering, 10, 9-14.

Burton, B. (1977). Diffusional creep of polycrystalline materials (Diffusion and Defect Monograph Series, Vol. 5). Bay Village, OH: Trans Tech Publications.

Bystricky, M., \& Mackwell, S. (2001). Creep of dry clinopyroxene aggregates with deformation in the dislocation creep. Journal of Geophysical Research, 106, 13443-13454.

Chakraborty, S. (1997). Rates and mechanisms of Fe-Mg interdiffusion in olivine at $980^{\circ}-1300^{\circ} \mathrm{C}$. Journal of Geophysical Research, 102(B6), $12317-12331$.

Coble, R. L. (1963). A model for boundary diffusion controlled creep in polycrystalline materials. Journal of Applied Physics, 34(6), 1679-1682.

Dimanov, A., \& Dresen, G. (2005). Rheology of synthetic anorthite-diopside aggregates: Implications for ductile shear zones. Journal of Geophysical Research, 110(7), 1-24. https://doi.org/10.1029/2004JB003431

Dimanov, A., \& Ingrin, J. (1995). Premelting and high-temperature diffusion of Ca in synthetic diopside: An increase of the cation mobility. Physics and Chemistry of Minerals, 22(7), 437-442.

Dimanov, A., Lavie, M. P., Dresen, G., Ingrin, J., \& Jaoul, O. (2003). Creep of polycrystalline anorthite and diopside. Journal of Geophysical Research, 108(B1), 2061. https://doi.org/10.1029/2002jb001815

Dimanov, A., Rybacki, E., Wirth, R., \& Dresen, G. (2007). Creep and strain-dependent microstructures of synthetic anorthite-diopside aggregates. Journal of Structural Geology, 29(6), 1049-1069. https://doi.org/10.1016/j.jsg.2007.02.010

Dohmen, R., Chakraborty, S., \& Becker, H. W. (2002). Si and O diffusion in olivine and implications for characterizing plastic flow in the mantle. Geophysical Research Letters, 29(21), 26-1-26-4. https://doi.org/10.1029/2002GL015480

Fei, H., Koizumi, S., Sakamoto, N., Hashiguchi, M., Yurimoto, H., Marquardt, K., et al. (2016). New constraints on upper mantle creep mechanism inferred from silicon grain-boundary diffusion rates. Earth and Planetary Science Letters, 433, 350-359.

Frost, H. J., \& Ashby, M. F. (1982). Deformation mechanism maps: the plasticity and creep of metals and ceramics (pp. 6-16). Oxford, England: Pergamon Press. Retrieved from http://publications.eng.cam.ac.uk/372960/

Ghosh, S., Bose, S., Mandal, N., \& Dasgupta, S. (2016). Dynamic recrystallization mechanisms and their transition in the Daling Thrust (DT) zone, Darjeeling-Sikkim Himalaya. Tectonophysics, 674(1), 166-181. https://doi.org/10.1016/j.tecto.2016.02.023

Guignard, J., Bystricky, M., \& Béjina, F. (2011). Dense fine-grained aggregates prepared by spark plasma sintering (SPS), an original technique in experimental petrology. European Journal of Mineralogy, 23(3), 323-331.

Hansen, L. N., Zimmerman, M. E., \& Kohlstedt, D. L. (2011). Grain boundary sliding in San Carlos olivine: Flow law parameters and crystallographic-preferred orientation. Journal of Geophysical Research, 116(8), 1-16. https://doi.org/10.1029/2011JB008220

Herring, C. (1950). Diffusional viscosity of a polycrystalline solid. Journal of Applied Physics, 21(5), 437-445.

Hidas, K., Garrido, C. J., Tommasi, A., Padrón-Navarta, J. A., Thielmann, M., Konc, Z., et al. (2013). Strain localization in pyroxenite by reaction-enhanced softening in the shallow subcontinental lithospheric mantle. Journal of Petrology, 54(10), $1997-2031$.

Hier-Majumder, S., Mei, S., \& Kohlstedt, D. L. (2005). Water weakening of clinopyroxenite in diffusion creep. Journal of Geophysical Research, 110(7), 1-12. https://doi.org/10.1029/2004JB003414

Hirth, G., \& Kohlstedt, D. L. (2003). Rheology of the upper mantle and the mantle wedge: A view from the experimentalists. In J. E. Eiler (Ed.), Inside the Subduction Factory (Vol. 138, pp. 83-105). Washington, DC: American Geophysical Union. https://doi. org/10.1029/138GM06

Holland, T. J. B., \& Powell, R. (2011). An improved and extended internally consistent thermodynamic dataset for phases of petrological interest, involving a new equation of state for solids. Journal of Metamorphic Geology, 29(3), 333-383. https://doi. org/10.1111/j.1525-1314.2010.00923.x

Holm, K., Embury, J. D., \& Purdy, G. R. (1977). The structure and properties of microduplex Zr-Nb alloys. Acta Metallurgica, 25(10), 1191-1200.

Ingrin, J., Pacaud, L., \& Jaoul, O. (2001). Anisotropy of oxygen diffusion in diopside. Earth and Planetary Science Letters, 192(3), 347-361. Koizumi, S., Hiraga, T., \& Suzuki, T. S. (2020). Vickers indentation tests on olivine: size effects. Physics and Chemistry of Minerals, 47(2), 8.

Koizumi, S., Hiraga, T., Tachibana, C., Tasaka, M., Miyazaki, T., Kobayashi, T., et al. (2010). Synthesis of highly dense and fine-grained aggregates of mantle composites by vacuum sintering of nano-sized mineral powders. Physics and Chemistry of Minerals, 37(8), 505-518. https://doi.org/10.1007/s00269-009-0350-y

Lifshitz, I. M., \& Sliyozov, V. V. (1961). The kinetics of precipitation from supersaturatedsolid solutions. Journal of Physics and Chemistry of Solids, 19, 35-50.

Nabarro, F. R. N. (1948). Deformation of crystals by the motion of single ions (pp. 75-90). Report of a Conference on the Strength of Solids. Bristol, UK.

Nakakoji, T., \& Hiraga, T. (2018). Diffusion creep and grain growth in forsterite +20 vol $\%$ enstatite aggregates: 2 . Their common diffusional mechanism and its consequence for weak-temperature-dependent viscosity. Journal of Geophysical Research: Solid Earth, 123(11), 9513-9527. https://doi.org/10.1029/2018JB015819 
Nakakoji, T., Hiraga, T., Nagao, H., Ito, S., \& Kano, M. (2018). Diffusion creep and grain growth in forsterite +20 vol\% enstatite aggregates: 1. High-resolution experiments and their data analyses. Journal of Geophysical Research: Solid Earth, 123(11), 9486-9512. https://doi. org/10.1029/2018JB015818

Peslier, A. H., Luhr, J. F., \& Post, J. (2002). Low water contents in pyroxenes from spinel-peridotites of the oxidized, sub-arc mantle wedge. Earth and Planetary Science Letters, 201(1), 69-86.

Rybacki, E., \& Dresen, G. (2000). Dislocation and diffusion creep of synthetic anorthite aggregates. Journal of Geophysical Research, 105(B11), 26017-26036.

Skemer, P., Warren, J. M., Kelemen, P. B., \& Hirth, G. (2010). Microstructural and rheological evolution of a mantle shear zone. Journal of Petrology, 51(1-2), 43-53.

Tasaka, M., \& Hiraga, T. (2013). Influence of mineral fraction on the rheological properties of forsterite + enstatite during grain-size-sensitive creep: 1. Grain size and grain growth laws. Journal of Geophysical Research: Solid Earth, 118(8), 3970-3990. https://doi.org/10.1002/ jgrb. 50285

Tasaka, M., Hiraga, T., \& Zimmerman, M. E. (2013). Influence of mineral fraction on the rheological properties of forsterite + enstatite during grain-size-sensitive creep: 2. Deformation experiments. Journal of Geophysical Research: Solid Earth, 118(8), 3991-4012. https:// doi.org/10.1002/jgrb.50284

Toy, V. G., Newman, J., Lamb, W., \& Tikoff, B. (2010). The role of pyroxenites in formation of shear instabilities in the mantle: Evidence from an ultramafic ultramylonite, Twin Sisters massif, Washington. Journal of Petrology, 51(1-2), 55-80.

Wagner, C. (1961). Theory of the aging of precipitation by redissolving (Ostwald ripening). Journal of Electrochemistry, 65(7-8), 581-591.

Wang, J. N. (2000). An investigation of the deformation mechanism in grain size-sensitive Newtonian creep. Acta Materialia, 48(7), $1517-1531$.

Warren, J. M., \& Hirth, G. (2006). Grain size sensitive deformation mechanisms in naturally deformed peridotites. Earth and Planetary Science Letters, 248(1-2), 438-450.

Weertman, J. (1999). Microstructural mechanisms of creep. In M. A. Meyers, R. W. Arm-strong, \& H. Kirschner (Eds.), Mechanics and materials: Fundamentals and linkages (pp. 451-488). New York, NY: John Wiley \& Sons Press.

Yabe, K., \& Hiraga, T. (2020). Grain boundary diffusion creep of olivine: 2. Solidus effects and consequences for the viscosity of the oceanic upper mantle. Journal of Geophysical Research: Solid Earth, 125(8), e2020JB019416. https://doi.org/10.1029/2020JB019416

Yabe, K., Sueyoshi, K., \& Hiraga, T. (2020). Grain boundary diffusion creep of olivine: 1. Experiments at 1 atm. Journal of Geophysical Research: Solid Earth, 125(8), e2020JB019415. https://doi.org/10.1029/2020JB019415

Yasuda, A. (2014). A new technique using FT-IR micro-reflectance spectroscopy for measurement of water concentrations in melt inclusions. Earth, Planets and Space, 66(1), 34

Zhao, N., Hirth, G., Cooper, R. F., Kruckenberg, S. C., \& Cukjati, J. (2019). Low viscosity of mantle rocks linked to phase boundary sliding. Earth and Planetary Science Letters, 517, 83-94. https://doi.org/10.1016/j.epsl.2019.04.019

Zhao, Y. H., Zimmerman, M. E., \& Kohlstedt, D. L. (2009). Effect of iron content on the creep behavior of olivine: 1 . Anhydrous conditions Earth and Planetary Science Letters, 287(1-2), 229-240. 